\title{
A Review on Applications of Layered Phosphorus in Energy Storage
}

\author{
Cheng Liu ${ }^{1} \cdot$ Yinghao Wang ${ }^{1} \cdot$ Jie Sun ${ }^{1,2} \cdot$ Aibing Chen $^{3}$
}

Received: 5 November 2019 / Revised: 18 November 2019 / Accepted: 3 December 2019 / Published online: 20 January 2020

(c) The Author(s) 2020

\begin{abstract}
Phosphorus in energy storage has received widespread attention in recent years. Both the high specific capacity and ion mobility of phosphorus may lead to a breakthrough in energy storage materials. Black phosphorus, an allotrope of phosphorus, has a sheet-like structure similar to graphite. In this review, we describe the structure and properties of black phosphorus and characteristics of the conductive electrode material, including theoretical calculation and analysis. The research progress in various ion batteries, including lithium-sulfur batteries, lithium-air batteries, and supercapacitors, is summarized according to the introduction of black phosphorus materials in different electrochemical applications. Among them, with the introduction of black phosphorus in lithium-ion batteries and sodium-ion batteries, the research on the properties of black phosphorus and carbon composite is introduced. Based on the summary, the future development trend and potential of black phosphorus materials in the field of electrochemistry are analyzed.
\end{abstract}

Keywords Layered phosphorus $\cdot$ Topological construction $\cdot$ Batteries $\cdot$ Supercapacitor

\section{Introduction}

With the deterioration of the natural environment and exhaustion of resources, the development, and utilization of clean energy has received much attention. Researchers are committed to developing sustainable energy based on wind and solar power; however, these sources are dependent on natural conditions $[1,2]$. Compared with wind and solar power, electric energy, such as rechargeable batteries, is efficient, safe, and affordable. As a result, electric energy has

Cheng Liu and Yinghao Wang have contributed equally to this work.

$\triangle$ Jie Sun

jies@tju.edu.cn

$\triangle$ Aibing Chen

chen_ab@163.com

1 Key Laboratory for Green Chemical Technology of Ministry of Education, School of Chemical Engineering and Technology, Tianjin University, Tianjin 300072, China

2 State Key Laboratory of Organic-Inorganic Composites, Beijing University of Chemical Technology, Beijing 100029, China

3 College of Chemical and Pharmaceutical Engineering, Hebei University of Science and Technology, Shijiazhuang 050018, China received more attention in recent years. Among rechargeable batteries, lithium-ion batteries (LIBs) have high power density, long service life, no memory loss, and are environmentally friendly. As a result, they have become the most notable power source for portable electronics and vehicles [3-5]. However, the shortage of lithium resources and limitations of geographical conditions are in conflict with the future energy demand [6-8]. Therefore, the development of new battery systems and optimization of existing batteries are the focus of electrochemical subject research. For example, compared with lithium, sodium has a wide range of applications and abundant reserves that are suitable for the development of large-scale energy storage equipment [7, 9-11]. In both the lithium-/sodium-ion battery systems, a positive or negative electrode material could strongly determine the electrochemical performance of the batteries.

Cathode material research has made very good progress, and more developed potential cathode materials are recognized, but the development of anode materials also needs attention [12,13]. Graphite is widely used as an anode material for LIBs because of its excellent charge and discharge performance. However, the same reaction does not occur in the case of sodium $[11,14]$. The non-graphitizable carbon materials with larger interlinear distance, such as hard carbon, are widely used as anode for sodium-ion batteries (SIBs) [15-17]. However, its low capacity of only 
250-300 $\mathrm{mAh} / \mathrm{g}$ and rapid capacity decay are the main issues that restrict their development [18-20]. Therefore, research on other anode materials is required. It is well known that silicon is considered a promising anode material and exhibits a theoretical specific capacity of $4200 \mathrm{mAh} / \mathrm{g}$ for LIBs. However, electrochemical inertia is a major problem that restricts the development of silicon materials in SIBs [21, 22]. Phosphorus is electrochemically active for both lithiation and sodiation with a considerable capacity $(2596 \mathrm{mAh} / \mathrm{g})$, as well as low cost. Consequently, it is a promising anode material for LIBs and SIBs, as well as other types of ion batteries, solar cells and capacitors.

The energy density of LIBs/SIBs for electric vehicles is currently around $260 \mathrm{Wh} / \mathrm{kg}$, which is insufficient for high demand electric vehicles with respect to the power [23, 24]. Application of a lithium-sulfur battery (LSB) is a more common method to improve the power [25, 26]. However, due to the strong solubility of lithium polysulfide in the electrolyte, developing a LSB system with a high energy density requires additional research [27-29]. Introduction to the use of phosphorus materials to optimize LSBs is also a part of this review.

Another alternative to address the limitations of LIBs is to develop lithium-air batteries (LABs) that could provide a theoretical energy density of about $3500 \mathrm{Wh} / \mathrm{kg}$ based on the $\mathrm{Li}+\mathrm{O}_{2} \leftrightarrow \mathrm{Li}_{2} \mathrm{O}_{2}$ reversible reaction [30,31]. Despite such great potential, practical application of LABs is restrained by some challenges, such as high overpotential, large polarization, and poor reversibility derived from the intrinsic sluggish kinetics of the electrochemical oxygen reduction (ORR) and oxygen evolution reactions (OER), and the safety issues that arise from lithium dendrites [32, 33]. To address these issues, phosphorus has been used as a protective layer for the lithium anode and a decorating material for the catalyst in the cathode of LABs that will be discussed in this review.

Several excellent reviews on the basic science of nanostructured energy materials, including phosphorus-based materials, have been recently published [34-37]. However, the systematic summarization of black phosphorus in energy storage materials, especially in potassium-ion batteries (PIBs), LABs, supercapacitors, and all-solid-state LIBs, is still necessary. In this review, we outline recent research on the application of black phosphorus in energy storage. By the summary of several early reviews and the collation of related research fields, the important research progress of phosphorus, especially black phosphorus, in the field of electrochemistry is introduced. The application of black phosphorus in various application fields is introduced, including LIBs, SIBs, PIBs, magnesium-ion batteries (MIBs), LSBs, LABs, and supercapacitors. For LIB/SIBs, we conducted a detailed and extensive review based on the size of the phosphorus. We also discuss blue phosphorus because of its graphene structure having electrochemical properties of interest, as an electrode material, which therefore has great prospects. We expect that this work summarizing pioneering research can be used to promote further development of energy storage in black phosphorus. In addition, since the application of black phosphorus in many fields is still in its early stage, we also discuss and predict the future of such applications. Finally, we present insights into the opportunities and challenges of black phosphorus and its composites in the field of electrochemistry.

\section{Black Phosphorus and Its Allotropes}

White phosphorus, red phosphorus, and black phosphorus are the three most common allotropes of phosphorus. In white phosphorus, one molecule has four phosphorus atoms (P4) with a tetrahedral structure [38]. Under normal conditions, white phosphorus has three crystal forms of $\alpha, \beta$ (Fig. 1a), and $\gamma$ (Fig. 1b) [39-41]. However, the high flammability, toxicity, and activity of white phosphorus restrict its application in energy storage materials [42, 43]. A P-P bond in the white phosphorus molecule is opened and connected to other white phosphorus molecules to form a chain structure, thereby forming a red phosphorus structure (Fig. 1c). This microscopic change can be achieved by gentle heating in an inert gas $\left(\sim 250^{\circ} \mathrm{C}\right)$ or exposure to sunlight [44]. Red phosphorus usually exists as an amorphous form and can be transformed to crystalline red phosphorus (called Hittorf's or violet phosphorus, Fig. 1d) by heating with small amounts of iodine [45].

Black phosphorus formed by stacking the phosphorene sheets through the van der Waals force between the layers usually exists in an orthorhombic crystal form (Fig. 1e) [46]. In addition, black phosphorus has other crystal forms, such as a hexagonal (Fig. 1f) and a simple cubic (Fig. 1g) [47, 48]. In the black phosphorus layer, the atomic connection is a chair structure, while the blue phosphorus layer is a hexagonal structure. Since black phosphorus has a structure similar to graphite, it has some graphite-like properties. Interestingly, another two-dimensional phosphorus allotrope, blue phosphorus (Fig. 1h), which has a layered honeycomb structure and high stability, has been prepared on the $\mathrm{Au}$ (111) substrate through an epitaxially grown method derived from black phosphorus [49].

The synthesis of black phosphorus has received increasing attention. Initially, black phosphorus was prepared by the treatment of white phosphorus at $200{ }^{\circ} \mathrm{C}$ and a pressure of 1.2 MPa (5-30 min) [50]. Considering that white phosphorus is toxic and flammable, the more chemically stable red phosphorus replaced white phosphorus as a raw material. Shirotani et al. [51] reported that large single crystals of black phosphorus were produced at $270{ }^{\circ} \mathrm{C}$ and $3.8 \mathrm{GPa}$ using red phosphorus. On this basis, Akahama et al. [52] 
(a)

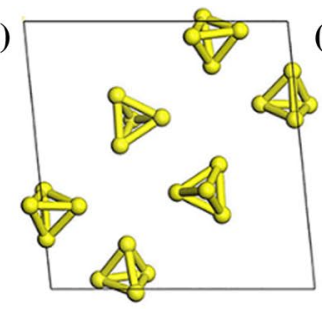

(e)
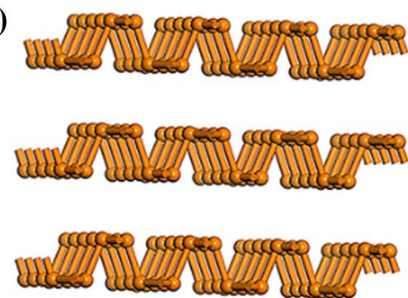

(b)

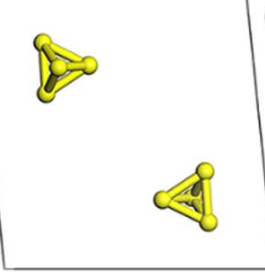

(f) (c)

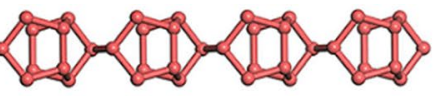

(d)
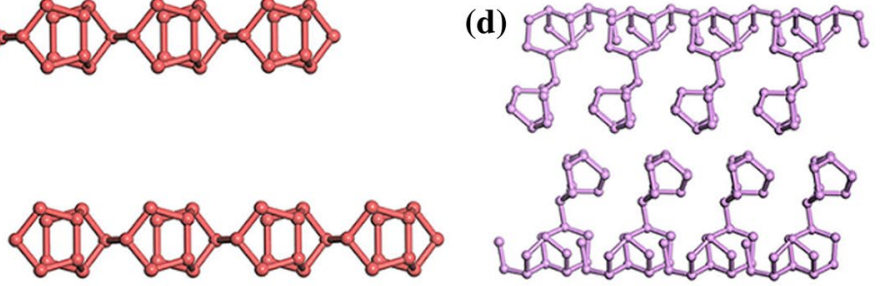

(g)

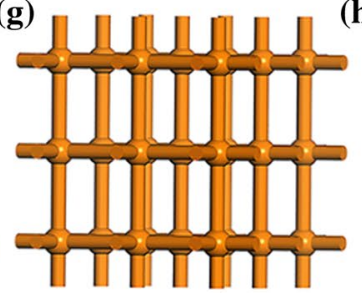

(h)

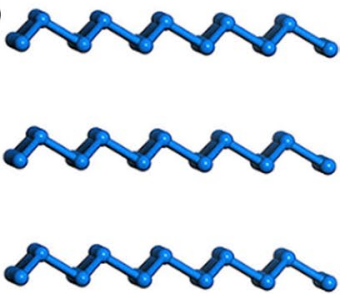

Fig. 1 Structural features of phosphorus allotropes: a $\beta$-white; $\mathbf{b} \gamma$-white; $\mathbf{c}$ red; $\mathbf{d}$ violet; $\mathbf{e}$ orthogonal phase black; $\mathbf{f}$ hexagonal phase black; $\mathbf{g}$ simple cubic phase black; h blue

developed a new method to melt red phosphorus at $900{ }^{\circ} \mathrm{C}$ and convert it to black phosphorus followed by cooling at $1 \mathrm{GPa}$. However, considering the toxicity of this method and stringency of the high-pressure conditions, Park and Sohn [53] reported a safer and more facile method of highenergy ball-milling, in which steel balls and a steel container were used for milling up to $54 \mathrm{~h}$, causing red phosphorus to transform into black phosphorus. The reason why red phosphorus can be transformed into black phosphorus during this milling process is that the local pressure and temperature can reach about $\sim 6 \mathrm{GPa}$ and $\sim 200{ }^{\circ} \mathrm{C}$, respectively. Recently, Nilge et al. [54] identified mild reaction conditions to prepare highly crystalline black phosphorus under vacuum using red phosphorus as a raw material and $\mathrm{Au}, \mathrm{Sn}$, and $\mathrm{SnI}_{4}$ as mineralizers. The significant advantage of this method is the ability to avoid toxicity and impurities during the reaction. Although there are many methods for preparing black phosphorus, further improvements in the purity and yield require further research.

\section{Application of Black Phosphorus in Lithium-Ion and Sodium-Ion Batteries}

Black phosphorus and red phosphorus have broad application prospects in electrochemistry. The different electrochemical properties of black phosphorus and red phosphorus are derived from their different structures. The structure of black phosphorus is similar to that of graphite; it can be firmly connected in the same plane by bonds between atoms to form a layered structure. The different layers are connected by van der Waals forces. In bulk black phosphorus, the layer-to-layer stacking order is AB-stacked, where every other layer is shifted by a half unit cell along the
[100] direction (Fig. 2a, b) [55]. This structure allows black phosphorus to have a higher ion mobility $\left(\sim 1000 \mathrm{~cm}^{2} / \mathrm{Vs}\right.$ at ambient temperature) [56]. Moreover, black phosphorus also shows some unique properties due to the pleated structure. Significant differences in the acoustic sound bandwidth between different directions by first-principal simulation [57] indicate the anisotropy of the black phosphorus. In addition, some simulations reported that black phosphorus also exhibits anisotropy of high electric conductivity and low lattice thermal conductivity in the armchair direction, as well as the insertion/extraction of sodium/lithium ions in the zigzag direction [58]. Researchers expanded the application of black phosphorus anodes by exploring its electrochemical mechanism. The improvement in electrode performance by combining black phosphorus and carbon materials with different topologies is a key point of this paper.

\section{The Mechanism of Lithium/Sodium Storage}

Red phosphorus and black phosphorus anodes have very similar lithiation/sodiation reaction mechanism, both of which can form $\mathrm{Li}_{3} \mathrm{P} / \mathrm{Na}_{3} \mathrm{P}$ in a fully discharged state, thus having a high theoretical specific capacity of $2596 \mathrm{mAh} / \mathrm{g}$ [59-61]. Unlike lithiation in red phosphorus, which only involves a one-step synthesis reaction, black phosphorus has two steps of sequential insertion, and alloying during the reaction. For the first step, $\mathrm{Li} / \mathrm{Na}$ are inserted between the interlayers of black phosphorus (Fig. 2c) [62]. The P-P bond is stable for lithiation until the formation of $\mathrm{Li}_{0.19} \mathrm{P}$, but more Li insertion breaks the P-P bond. Interestingly, more sodium can be stored without $\mathrm{P}-\mathrm{P}$ bond cleavage to form $\mathrm{Na}_{0.25} \mathrm{P}$ [62]. Subsequently, the alloying process occurs and delivers 
(a)

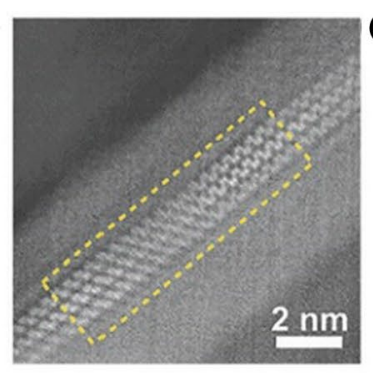

(c)

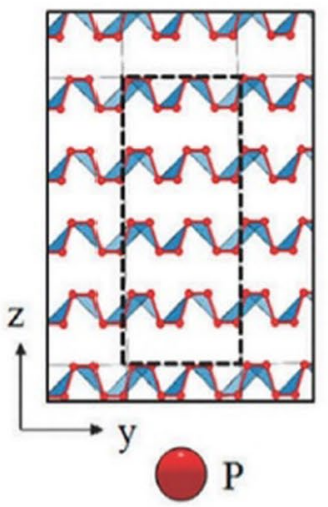

(b)

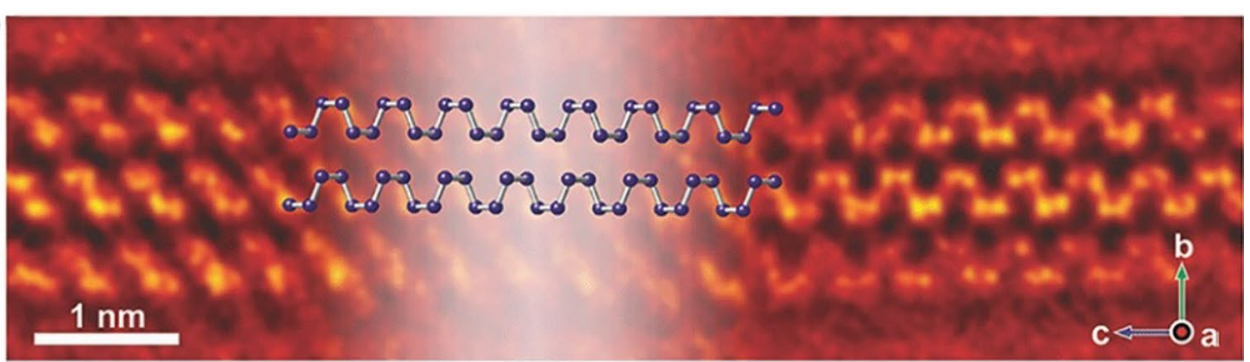

(d)

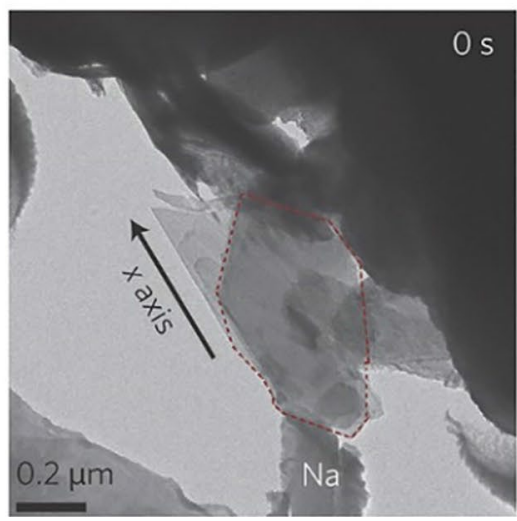

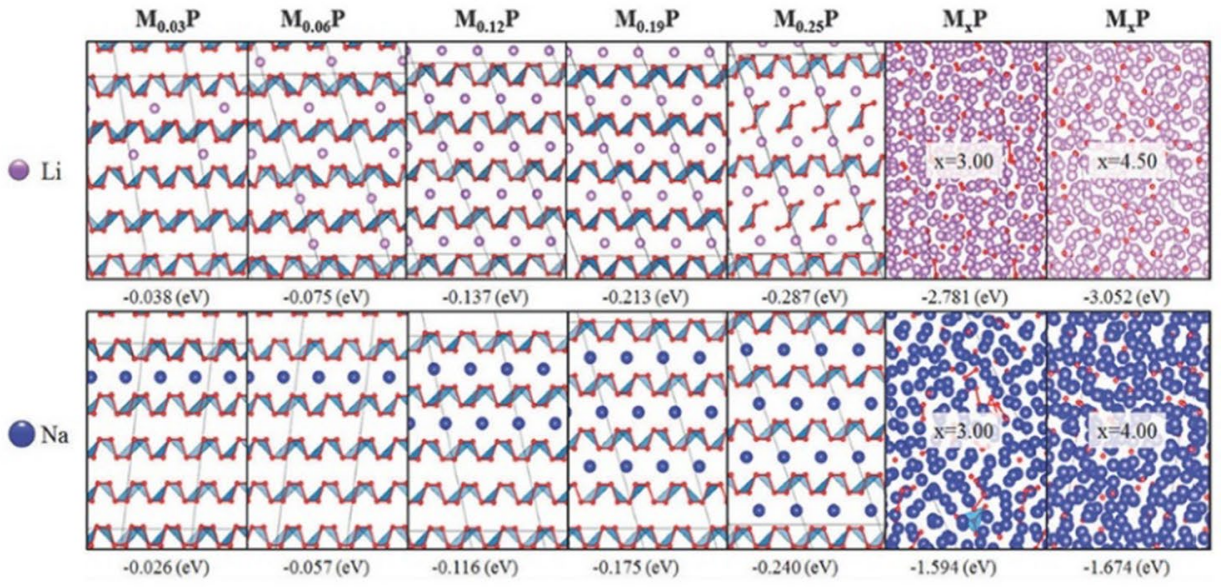
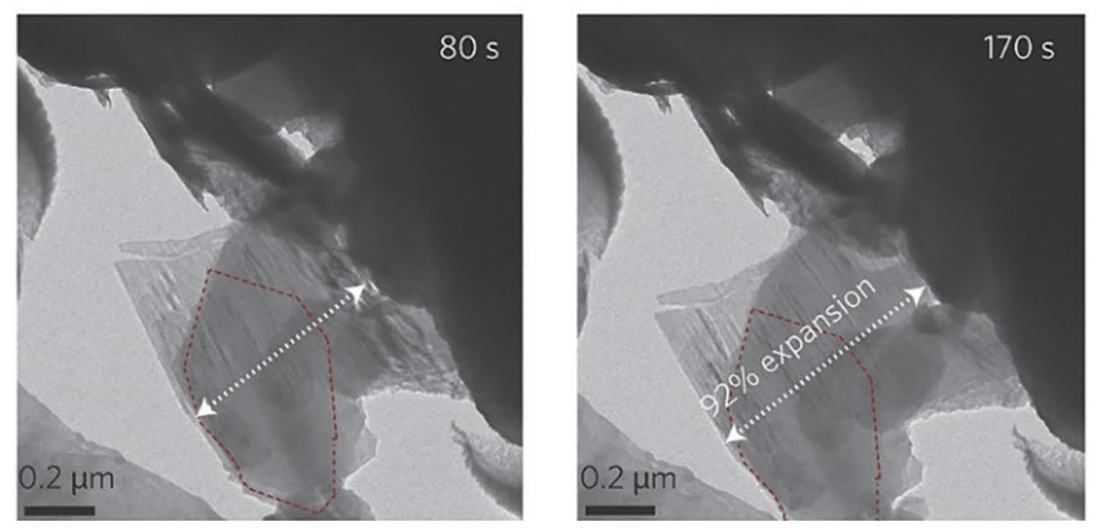

Fig. 2 a Annular dark-field scanning transmission electron microscopy (ADF-STEM) image of a black phosphorus flake and b corresponding magnified image of the region highlighted in a [55]; c insertion mechanism in black phosphorus [62]; $\mathbf{d}$ time-lapse scanning transmission electron microscopy (TEM) images of sodiation in black phosphorus [65] major capacity but poor cyclic performance because of the huge volume expansion.

The diffusion of lithium ions in black phosphorus is anisotropic due to the different structures between phosphorene and graphene. In the zigzag direction, the diffusion energy barrier of lithium on the surface of the phosphorus is only $0.08 \mathrm{eV}$, while for the armchair direction, the barrier is $0.68 \mathrm{eV}$ [58]. A very small energy barrier along the zigzag direction ensures rapid diffusion of Li. Therefore, the diffusion path of lithium is in the Z-shaped phosphorus direction. Lithium can be quantified, and the charging circuit can be associated with the rate of diffusion on the electrode material. The diffusion coefficient $(D)$ can be obtained by Eq. 1 [63]:

$D=D_{0} \exp \left(-\frac{E_{\mathrm{a}}}{k_{\mathrm{B}} T}\right)$

where $E_{\mathrm{a}}$ is the diffusion barrier; $k_{\mathrm{B}}$ is the Boltzmann constant $\left(k_{\mathrm{B}}=1.38 \times 10^{-23} \mathrm{~J} / \mathrm{K}\right) ; D_{0}$ is the pre-factor; and $T$ is the temperature in Kelvin. The small lithium diffusion barrier $(0.08 \mathrm{eV})$ along the zigzag direction of black phosphorus increases the diffusivity to $1.4 \times 10^{4}$ times that of perfect graphene $(0.372 \mathrm{eV})[58,64]$. 
Both red phosphorus and black phosphorus anodes would suffer large volume expansion-contraction changes during the lithium/sodium alloying-dealloying electrochemical process. However, unlike the isotropic volume swelling of red phosphorus, the volume expansion of black phosphorus during the reaction is anisotropic (Fig. 2d) [65], which mainly occurs in the second step of the alloying reaction. Regarding the characteristics of the black phosphorus volume expansion process, more constraints should be considered in practical application to design the space to cope with the volume expansion. In order to solve the volume expansion, researchers proposed the following solutions. (1) Reducing the diffusion distance of the high ion diffusion energy barrier, reducing the black phosphorus, especially the grain size along the armchair, can improve rate performance. (2) Introduction of heteroatom doping and vacancies can, respectively, reduce their diffusion energy barrier or provide a new diffusion channel for lithium ions, and adjust the adsorption binding energy of lithium.

\section{Topological Construction of Black Phosphorus}

Black phosphorus has great potential as an electrode material, but its anisotropic ion diffusion path causes a negative effect on lithium/sodium storage performance. Additionally, anisotropic volume expansion (300\% [66] and 500\% [65] at full lithiation and sodiation, respectively) will affect the life of the electrode material of black phosphorus.

In order to solve the problems caused by volume expansion, researchers proposed a method to construct a binary topology framework of a black phosphorus-carbon composite. The topological structure and combination of black phosphorus and various carbons can be summarized into three binary topologies: 0D @ 0D, 0D @ 1D and 2D @ 2D. In the subsequent sections of this article, we will introduce each topology and the related research separately.

\section{OD Black Phosphorus and OD Carbon}

It is theoretically possible to achieve performance improvements by reducing the black phosphorus particle size. In 2007, Park and Sohn [53] reported that black phosphorus can be used as an active material for lithium storage. Black phosphorus was converted by commercially available, amorphous red phosphorus using high-energy mechanical milling techniques. The particle size of the phosphorus was reduced by a ball-milling process. The simple use of phosphorus as the anode material can produce a high capacity, but after several cycles, large attenuation occurs that affects subsequent use. Therefore, Park and John [53] increased the conductivity of the composite using a modified method, in which carbon black and black phosphorus were combined. At the same time, the low cutoff voltage was limited up to $0.78 \mathrm{~V}$ and the lithium penetration was controlled, using the stable reversible reaction between $\mathrm{P}$ and lower LiP. This method reduced the volume expansion of black phosphorus but provided the reversible specific capacity of only $600 \mathrm{mAh} / \mathrm{g}$ and sacrificed its high theoretical specific capacity.

The reversible and theoretical specific capacity was improved by making a composite of black phosphorus and graphite [67]. Such composite connected by a phosphoruscarbon bond $(\mathrm{P}-\mathrm{C})$ is a 0D black phosphorus@0D-graphite composite material, named BP-G (Fig. 3a). During the lithium insertion/extraction process, $\mathrm{P}-\mathrm{C}$ bonds maintain good stability with a very large electrically conductivity. Based on the electrochemical performance test, as compared to the mixture of graphite and phosphorus, this composite material shows a higher reversible specific capacity of $2270 \mathrm{mAh} / \mathrm{g}$ at a current density of $0.2 \mathrm{C}$. In addition to compounding black phosphorus and graphite, we also studied other carbon materials and found that graphite is the best material for composites. Very recently, Li et al. [68] embedded phosphorus in Ketjenblack (KB) via a high-energy milling method with a milling speed of $1000 \mathrm{r} / \mathrm{min}$ (denoted as P-KB). In this composite, the black phosphorus nanocrystals were homogenously dispersed in the carbon buffering matrix and chemically bonded by $\mathrm{P}-\mathrm{O}-\mathrm{C}$. Subsequently, a full cell based on such phosphorus-carbon composites against the $\mathrm{LiNi}_{1 / 3} \mathrm{Co}_{1 / 3} \mathrm{Mn}_{1 / 3} \mathrm{O}_{2}$ cathode was designed and it delivered an initial charge capacity of $1135 \mathrm{mAh} / \mathrm{g}$ (based on P-KB) with an initial Coulombic efficiency of $65.6 \%$. Such P-O-C chemical bond could also be formed between phosphorus and carbon nanotubes (CNTs) via a ball-milling process [69], contributing to close and robust contact between phosphorus and CNTs, thus improving the electrical conductivity.

\section{OD Black Phosphorus and 1D Carbon}

Other topological structures of 0D black phosphorus and 1D carbon have been studied, such as black phosphorus combined with CNTs and carbon fiber. In consideration of the weak interaction between black phosphorus and defect-free CNTs, the drawback is cycle stability. Recently, $\mathrm{Xu}$ et al. [70] introduced KB with high specific surface area $\left(1400 \mathrm{~m}^{2} / \mathrm{g}\right)$ and conductivity to bond with black phosphorus, which was subsequently combined with multi-walled carbon nanotubes (MWCNTs) to prevent the structure breakage, producing a composite named BPC (Fig. 3b). BPC demonstrated excellent cyclability that delivered a capacity of $\sim 1700 \mathrm{mAh} / \mathrm{g}$ after 100 cycles at $1.3 \mathrm{~A} / \mathrm{g}$. Zhao and co-workers [71] synthesized black phosphorus@fibrous red phosphorus@ MWCNT, named MWCNT@f-RP@BP (Fig. 3c), via a one-step mineralizer-assisted vapor phase method, in which amorphous and fibrous phosphorus were grown in situ on the surface of MWCNTs with a strong $\mathrm{P}-\mathrm{C}$ 
Fig. 3 a High-resolution transmission electron microscopy (HRTEM) image and schematic of black phosphorus@graphene composite [67]; b schematic for the structures of the BPC composite [70]; c scheme for the structures of MWCNT@fRP@BP [71] (a)

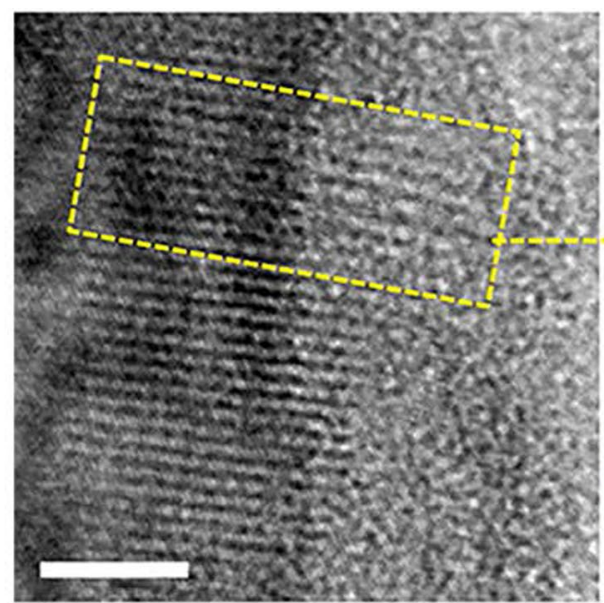

(b)

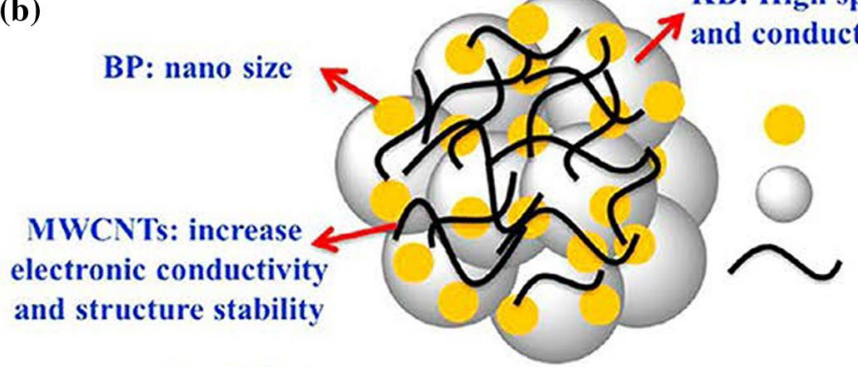

Black Phosphorus (BP)

Ketjenblack (KB)

MWCNTs

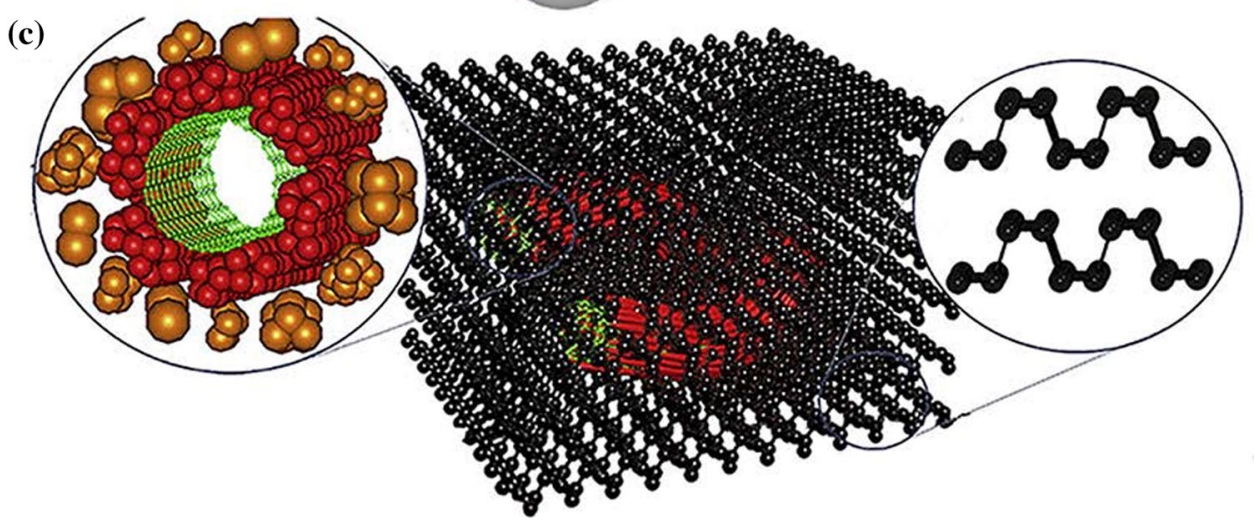

interaction. Electrochemical performance tests showed that this hybrid composite provided a specific capacity 3.5 times greater than that of the black phosphorus@ MWCNT composite at $500 \mathrm{~mA} / \mathrm{g}$ after 250 cycles. In order to increase the bonding between black phosphorus and carbon nanotubes, Haghighat-Shishavan et al. [72] controlled the air exposure on black phosphorus to yield a protective oxide layer and then combined it with carbon nanotubes to form a BP-CNTs composite. The BP-CNTs composite was further fabricated into anodes for both LIBs and SIBs. The composite exhibited excellent cycle stability with a specific capacity of $1177 \mathrm{mAh} / \mathrm{g}$ after 400 cycles at $520 \mathrm{~mA} / \mathrm{g}$ for the LIBs and $1092 \mathrm{mAh} / \mathrm{g}$ after 200 cycles at $520 \mathrm{~mA} / \mathrm{g}$ for the SIBs.

\section{D Black Phosphorus and 2D Carbon}

Compared with other structures, 2D nanostructures have great advantages in charge and discharge processes due to the short diffusion length of lithium/sodium ions and open charge transport channels. The current methods employed to achieve 2D black phosphorus nanomaterials are generally categorized into two basic approaches, "top-down" and "bottom-up." The top-down strategy (including mechanical exfoliation [73], liquid exfoliation [74], ultrasonicationbased exfoliation [75], and electrochemical methods [76]) generally focuses on bulk black phosphorus exfoliation under a driving force. However, this method remains difficult with respect to achieving large-scale uniform distribution of 
black phosphorus nanostructures. The "bottom-up" strategy is realized through chemical synthesis and direct fabrication of nanomaterial from a specific precursor material (including chemical vapor transport [77] and wet lab methods [78]). Zhang et al. [78] synthesized 2D porous black phosphorus-based nanosheets through the bottom-up assembly of phosphorus nanodomains using a wet-chemical solvothermal reaction. The nanopores in the phosphorus nanosheets can function as $\mathrm{Li}$-ion reservoirs for neighboring layers of phosphorus, facilitating ion access to the entire surface area. When used as LIBs, the phosphorus nanosheets delivered a capacity of $1683 \mathrm{mAh} / \mathrm{g}$ after 100 cycles at $200 \mathrm{~mA} / \mathrm{g}$.

In order to further optimize the electrochemical performance and enhance the structural stability of black phosphorus nanosheets, carbon-based materials can be introduced to construct hybrid electrodes. Chen et al. [79] synthesized a 2D black phosphorus@2D graphene (named BP-G) film by filtering the mixed dispersion of black phosphorus nanosheets (80 wt.\%) and graphene sheets. Applying this film to the anode of a LIB can exhibit a specific capacity of $402 \mathrm{mAh} / \mathrm{g}$ with an average Coulombic efficiency approaching $100 \%$ at a current density of $500 \mathrm{~mA} / \mathrm{g}$, showing excellent cycling performance. Simultaneously, we prepared a 2D phosphorene@2D graphene hybrid material made of few-layer phosphorene nanosheets sandwiched between wider graphene nanosheets [65]. Despite the anisotropic expansion during the sodiation process, the presence of a graphene interlayer structure can provide a buffer for this expansion (Fig. 4a). In addition, the phosphorene nanosheets also offer a short and effective diffusion distance for sodium ions. Moreover, the graphene layers were able to function as an electrical highway that enhances both the electrical conductivity of the material and provides a preferential pathway to the electrons generated by the redox reaction of phosphorene. Notably, due to the electrochemical inactivity of graphene for sodiation, the $\mathrm{C} / \mathrm{P}$ ratio was optimized to 2.78:1. After 100 cycles at a rate of $0.02 \mathrm{C}$, the cycle showed good retention at a specific capacity of $2080 \mathrm{mAh} / \mathrm{g}$, which is equivalent to $85 \%$ capacity retention, and only $0.16 \%$ per cycle. To further immobilize phosphorene and protect it from cracking during the sodiation and desodiation process, a sandwich structured phosphorene/graphene hybrid was prepared with the coinstantaneous introduction of $\mathrm{P}-\mathrm{C}$ and $\mathrm{P}-\mathrm{O}-\mathrm{C}$ bonds through a sonicating and heat-treating process [80]. Hence, this sandwich structured hybrid showed a high specific capacity $(2311 \mathrm{mAh} / \mathrm{g}$ at $100 \mathrm{~mA} / \mathrm{g})$, excellent rate capability, and cycling stability (with a capacity retention of 83.9\% after 100 cycles).

Recently, a layered black phosphorus/reduced graphene oxide $(\mathrm{BP} / \mathrm{rGO})$ electrode without carbon black or polymer binder additives was prepared by pressurization at ambient temperature, derived from a precursor of graphene layers wrapped around phosphorus (Fig. 4b) [81]. In the
$\mathrm{BP} / \mathrm{rGO}$ layered structure, excellent mechanical properties of the graphene layer buffer were obtained with the volume variation of black phosphorus during the cycling process, stabilizing the nanostructure. To further restrict the huge volume expansion of black phosphorus during the sodiation process and prevent contact loss of the black phosphorus/graphite with the current collector, black phosphorus/graphite particles were coated with polyaniline to form a ternary composite (Fig. 4c) [82]. This composite showed a cycling performance with a capacity retention of $1120 \mathrm{mAh} / \mathrm{g}$ after 100 cycles at $500 \mathrm{~mA} / \mathrm{g}$. Mei et al. [83] developed a unique $2 \mathrm{D}-\mathrm{TiO}_{2}-2 \mathrm{D}$ van der Waals heterostructured (black phosphorus/ $/ \mathrm{TiO}_{2} /$ porous graphene) hydrogel by coating black phosphorus particles on a porous graphene/ $\mathrm{TiO}_{2}$ composite hydrogel (Fig. 4d). Based on the formation of $2 \mathrm{D}-\mathrm{TiO}_{2}-2 \mathrm{D}$ heterostructures and a hierarchically porous structure, black phosphorus/ $/ \mathrm{TiO}_{2} /$ porous graphene delivered a considerable initial discharge capacity of $1336.1 \mathrm{mAh} / \mathrm{g}$ at $200 \mathrm{~mA} / \mathrm{g}$, good cycling life $(502 \mathrm{mAh} / \mathrm{g}$ for 180 cycles $)$ and excellent rate capability $(271.1 \mathrm{mAh} / \mathrm{g}$ at $5 \mathrm{~A} / \mathrm{g}$ ).

Another novel heterogeneous nanocomposite assembled from a $0 \mathrm{D}$ black phosphorus quantum dot and 2D $\mathrm{Ti}_{3} \mathrm{C}_{2}$ MXene nanosheet by $\mathrm{P}-\mathrm{O}-\mathrm{Ti}$ bonding interactions with the assistance of sonication and stirring (denoted as BPQD/TNS) was prepared and employed as an anode material for LIBs/SIBs [84]. The electrochemical behaviors of the heterogeneous nanocomposite were investigated. As shown in Fig. 5a, b, there are five peaks at 1.55, 1.39, 0.92, 0.78 and $0.14 \mathrm{~V}$ during the first cathodic scan, attributed to the multistep lithiation reactions with the transformation of black phosphorus to $\mathrm{Li}_{3} \mathrm{P}$ (Black phosphorus $\rightarrow \mathrm{LiP}_{7} \rightarrow \mathrm{LiP}_{5} \rightarrow \mathrm{Li}_{3} \mathrm{P}_{7} \rightarrow \mathrm{LiP} \rightarrow \mathrm{Li}_{3} \mathrm{P}$ ).

Although enormous breakthroughs in LIBs/SIBs were achieved, safety issues arising from gas production and leakage of the flammable organic electrolytes are not negligible [85-87]. A potential solution to this problem is the use of a solid-state electrolyte (based on a polymer and ceramic). However, few reports have been made about the use of a black phosphorus anode in an all-solid-state battery. In 2010, Nagao et al. [88] fabricated an all-solid LIB with a black phosphorous-based composite as the anode and $\mathrm{Li}_{2} \mathrm{~S}-\mathrm{P}_{2} \mathrm{~S}_{5}$ glass-ceramic as a solid electrolyte. The first discharge capacity was $1962 \mathrm{mAh} / \mathrm{g}$ at $1.47 \mathrm{~A} / \mathrm{g}$, and it exhibited excellent cyclic stability with $\sim 500 \mathrm{mAh} / \mathrm{g}$ after 150 cycles in the potential range from 0 to $2.5 \mathrm{~V}$. Despite acceptable performance, the synthesis of the $\mathrm{Li}_{2} \mathrm{~S}-\mathrm{P}_{2} \mathrm{~S}_{5}$ glass-ceramic required a harsh inert atmosphere and used active $\mathrm{Li}_{2} \mathrm{~S}$ as raw material, limiting its application as an all-solid LIB. Additionally, the high interface resistant between electrolyte and black phosphorus anode needs to be addressed. Table 1 summarizes the recent progress of black phosphorus-based anode materials for LIBs/SIBs. 

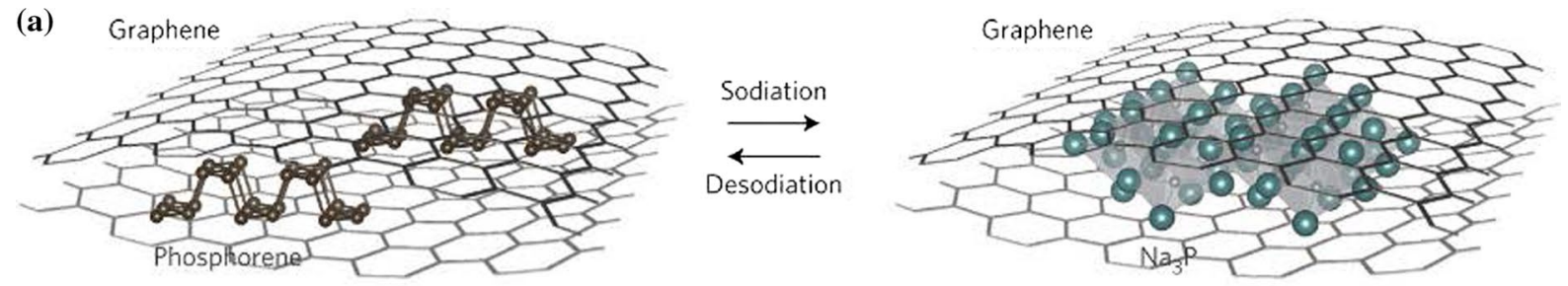

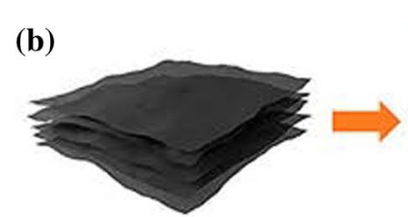

GO

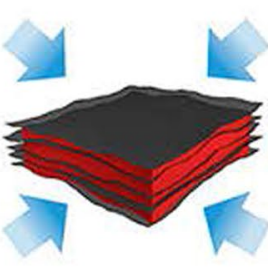

$\mathrm{RP} / \mathrm{rGO}$
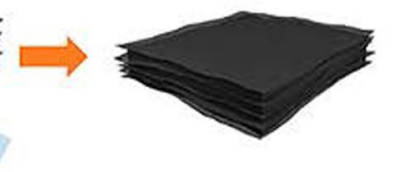

$\mathrm{BP} / \mathrm{rGO}$

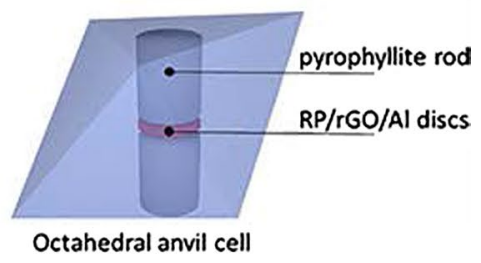

(c)

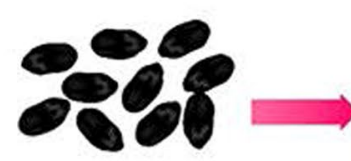

BP-G

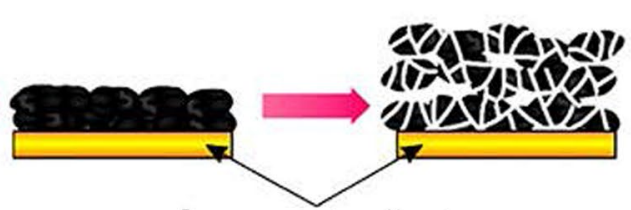

Cu current collector
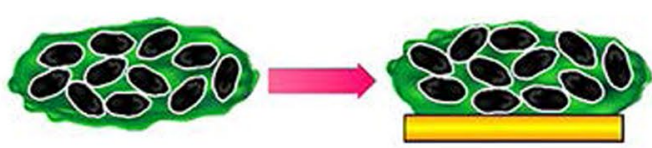

BP-GIPANI
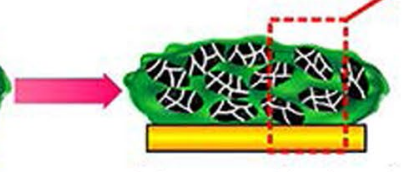

After sodiation/ desodiation process
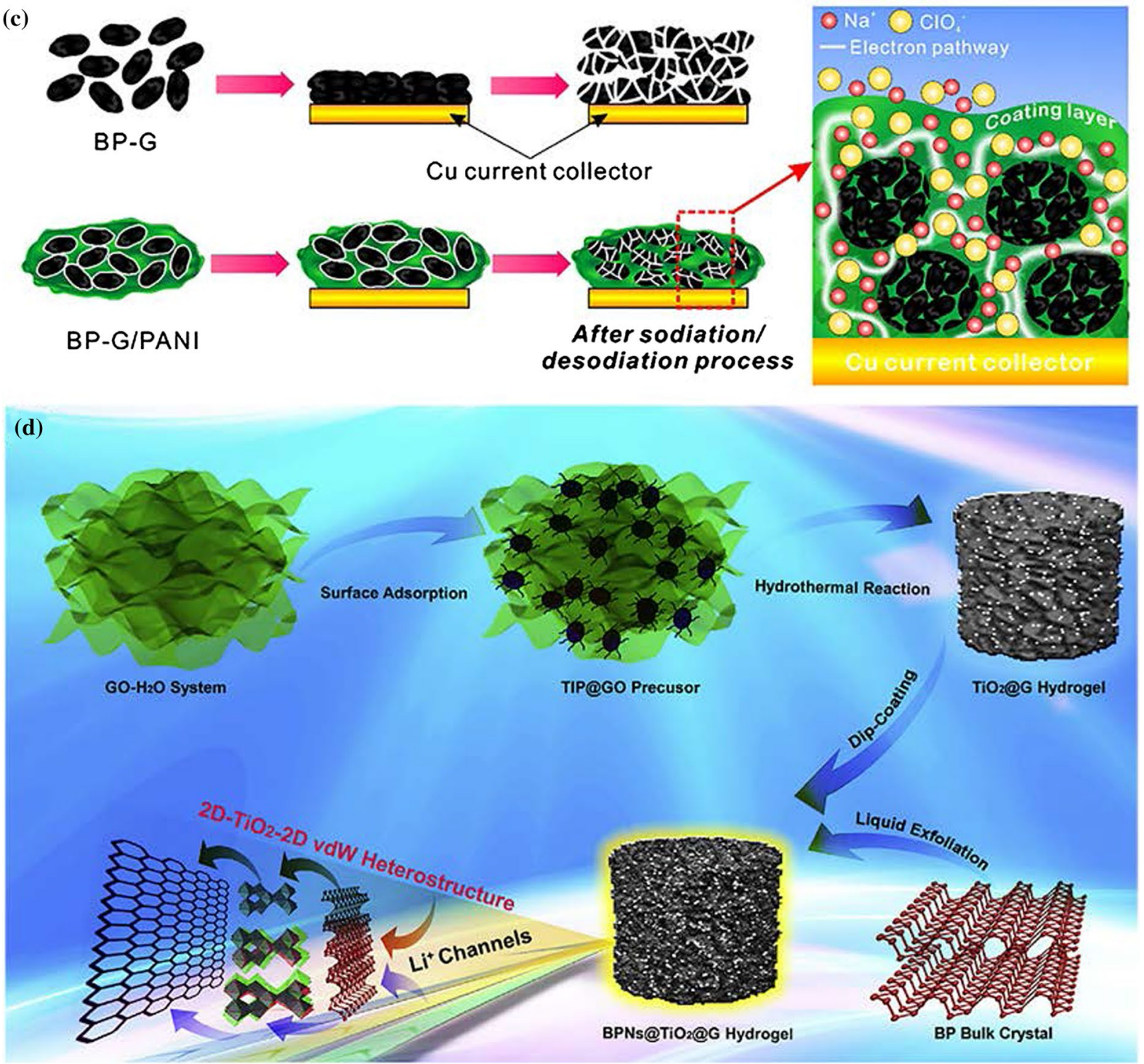

Fig. 4 a Structural evolution of the sandwiched phosphorene-graphene structure during sodiation [65]; b schematic description of the BP/rGO

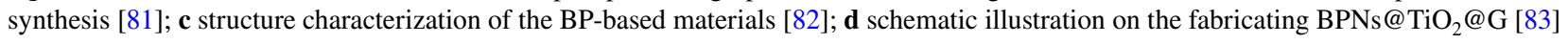


Fig. 5 a Schematic diagram showing several key states of the BPQD/TNS anode during the first $C V$ cathodic scan and $\mathbf{b}$ corresponding HRTEM images after the first discharge at $100 \mathrm{~mA} / \mathrm{g}$ [84]

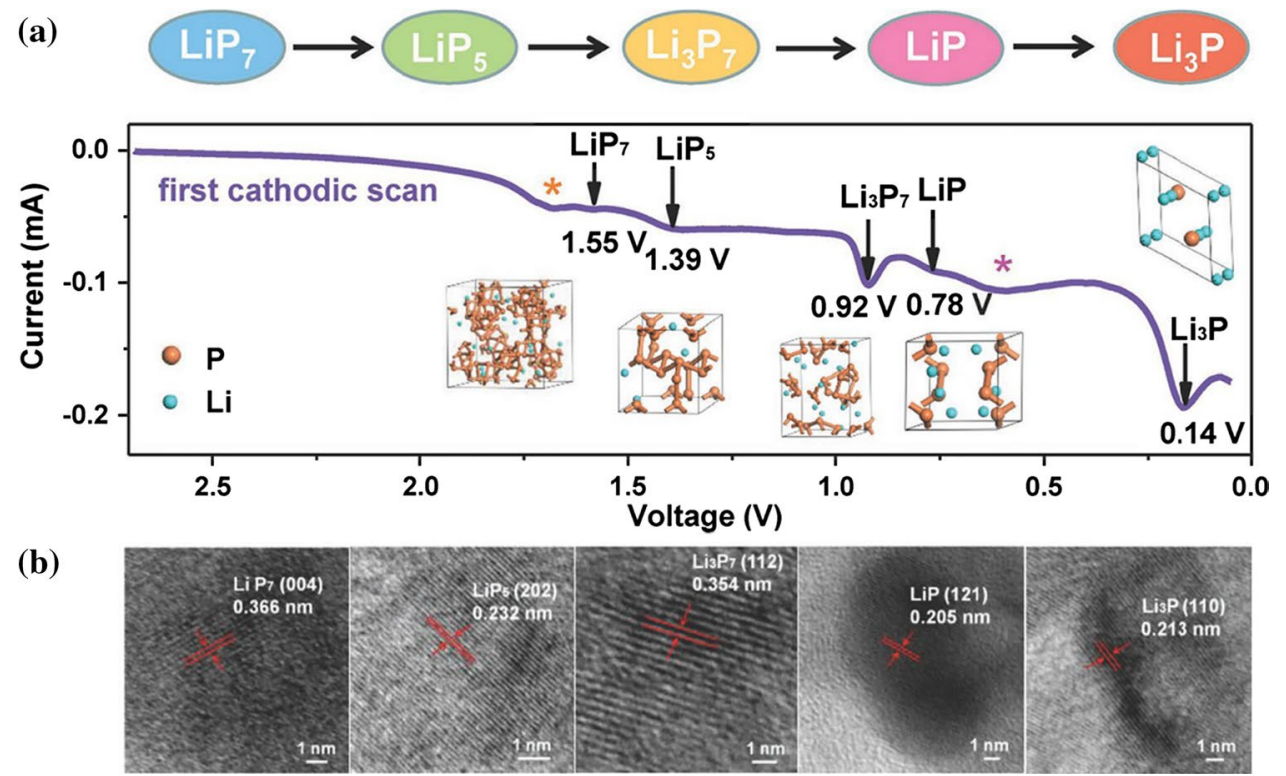

(b)

\section{Blue Phosphorus}

One isoform of phosphorus, blue phosphorus, is receiving more attention in recent years because of its special structure and electrochemical characteristics. Unlike graphene, blue phosphorus has a puckered structure, and the $\mathrm{P}$ atoms along its thickness belong to two atomic planes. As shown in Fig. 6a, the lattice parameters are $a=0.569 \mathrm{~nm}$ and $b=0.328 \mathrm{~nm}$ along the armchair and zigzag direction of monolayer blue phosphorus, respectively. The valence band maximum and conduction band minimum of blue phosphorus are near the $Y$ and $X$ valley, respectively, indicating that blue phosphorus is an indirect band gap semiconductor $\left(E_{\mathrm{g}}=1.9 \mathrm{eV}\right)$ [89]. Through the density functional theory (DFT) calculation on the basis of the model for a blue phosphorus monolayer on an $\mathrm{Au}$ (111) surface (Fig. 6b), the calculated adsorption energy for each phosphorus atom is $-0.27 \mathrm{eV}$, indicating that this blue phosphorus is stable [49]. As shown in Fig. 6c, an optimal path of Li diffusion is from a top site to the nearest neighboring top site passing through a hollow site with a small diffusion barrier $(0.16 \mathrm{eV})$ [90]. For sodiation, as shown in Fig. 6d, three geometrically unique adsorption sites (H-site, R-site, and F-site) were considered for $\mathrm{Na}$, with corresponding binding energies of $-0.94 \mathrm{eV}$, $-0.65 \mathrm{eV}$, and $-0.96 \mathrm{eV}$, respectively [91]. Thus, the optimized adsorption site was a F-site in Fig. $6 \mathrm{~d}(-0.96 \mathrm{eV})$, which was large enough to ensure stability and safety during operation. To develop high-performance blue phosphorus anodes, a blue phosphorus, and carbon heterostructure is necessary to improve electron conductivity of blue phosphorus. Fan et al. [92] investigated the diffusion properties of $\mathrm{Na}$ in the blue phosphorus/graphene heterostructure
(Figs. 6e-g) and found that the preferred diffusion of $\mathrm{Na}$ was along the blue phosphorus side of the blue phosphorus/ graphene heterostructure and the energy barrier decreased about $0.01 \mathrm{eV}$ compared to that of pristine blue phosphorus (Fig. 6f). Although calculations have demonstrated that blue phosphorus is suitable for storing $\mathrm{Li} / \mathrm{Na}$, there is no study on its experimental LIBs/SIBs.

\section{Other Ion Batteries}

The development of ion batteries is strong. The development of LIBs and SIBs is relatively mature. In the previous section, we introduced some applications of black phosphorus and black phosphide in these two ion batteries. In addition, black phosphorus is also used in other ion batteries.

\section{Potassium-Ion Battery}

A PIB is a new type of high-voltage secondary battery that could be used as a supplement or a substitute for LIBs in some fields. Since 2015, there have been reports of positive and negative materials for potassium batteries and complete battery research [93-97].

Graphite anode materials are considered for a PIB, but the theoretical capacity is only $279 \mathrm{mAh} / \mathrm{g}$. As previously mentioned, the phosphorus-based materials have a higher capacity relative to graphite. In 2017, Zhang et al. [98] proposed and demonstrated a PIB using a phosphorus-based material $\left(\mathrm{Sn}_{4} \mathrm{P}_{3}\right)$ as a negative electrode. Based on the detected KP final phase, the authors further proposed a possible reaction 
mechanism: $\mathrm{P}+\mathrm{K}+\mathrm{e}^{-} \leftrightarrow \mathrm{KP}$, providing a theoretical capacity of $865 \mathrm{mAh} / \mathrm{g}$. At the same time, the use of phosphorus alone does not achieve the best results. The conductive carbon matrix enhances the conductivity and works as a buffer to accommodate volume expansion/shrinking during discharging and charging, thus leading to a stable structure and the improvement in the electrochemical performance. Sultana et al. [99] prepared a black phosphorus/graphite composite via ball-milling as an anode material for a PIB. The secondary aggregated phosphorus/graphite particles displayed a broad size distribution ranging from hundreds of nanometers to tens of micrometers (Fig. 7a). Black phosphorus@graphite with a mass ratio of $m_{\mathrm{BP}} / m_{\mathrm{G}}=1: 1$ (BPC 1:1) displayed a capacity of $270 \mathrm{mAh} / \mathrm{g}$ after 50 cycles at $50 \mathrm{~mA} / \mathrm{g}$ (Fig. 7b). In order to enhance the contact between phosphorus and the carbon matrix and improve the structural stability of the phosphorus/carbon composite, $\mathrm{P}-\mathrm{C}$ or $\mathrm{P}-\mathrm{O}-\mathrm{C}$ chemical bonds were introduced between black phosphorus and carbon matrix by ball-milling of $20 \mathrm{wt} . \%$ red phosphorus and $80 \mathrm{wt} . \%$ graphite (shortly named a-P/C) (Fig. 7c) [100]. The modification increased the reversible capacity to $323.5 \mathrm{mAh} / \mathrm{g}$ after 50 cycles at $50 \mathrm{~mA} / \mathrm{g}$ (Fig. 7d). The phosphorus-based materials may provide a safe, low cost, and high-power density anode for PIBs.

\section{Magnesium-Ion Battery}

Magnesium ions have two electrons. MIBs have a specific capacity of up to $3833 \mathrm{mAh} / \mathrm{cm}^{3}[101,102]$, and they are abundant in source and high in safety. They are ideal for energy storage devices. However, compared to LIBs and SIBs, the polarization of divalent magnesium ions is strong, resulting in slow diffusion of $\mathrm{Mg}^{2+}$. In the simple substance of phosphorus, $\mathrm{Mg}^{2+}$ can be transported quickly, and the high capacity and low potential of phosphorus also meet the basic requirements of the electrode material of the MIBs.

Using DFT, we calculated the energy barrier of $\mathrm{Mg}^{2+}$ on a black phosphorus monolayer. As shown in Fig. 8, similar to the process of $\mathrm{Li}$-ion diffusion in black phosphorus, the diffusion energy barrier of magnesium ions along the zigzag direction is only $0.09 \mathrm{eV}$, while that along the armchair direction is greater $(0.56 \mathrm{eV})$ [103]. The formed $\mathrm{Mg}_{0.5} \mathrm{P}$ can still maintain the layered structure of black phosphorus without being destroyed, indicating that single layer of black phosphorus is an ideal electrode material for MIBs [104]. The construction of a special phosphorus-carbon binary topology can effectively exert a synergistic effect of phosphorus and carbon and has broad application prospects in MIBs. It is of great significance to reduce the energy barrier of magnesium-ion transport and adjust the intercalation layer spacing of magnesium-ion adaptation.

\section{Lithium-Sulfur Battery}

LSBs, a very promising energy storage device, have a high theoretical energy density $(2600 \mathrm{Wh} / \mathrm{kg})$ and are low cost and environmentally friendly $[105,106]$. However, LSBs also have shortcomings that restrain their development, such as the poor electronic conductivity of sulfur, the remarkable volume change of a sulfur cathode during cycling and the shuttle effect in organic electrolyte from the high solubility of the reaction intermediates $\left(\mathrm{Li}_{2} \mathrm{~S}_{x}\right.$, $4<x<8$ ). The shuttle effect creates a side reaction between polysulfide's and the lithium anode, which results in rapid decline in cycle life and capacity [106, 107]. The current improvement methods mainly include the modification of the sulfur cathode and the separator. The modified materials mainly include carbon-based materials, metal oxides, and metal sulfides.

Carbon-based materials typified by conductive carbon black, carbon nanotubes, and graphene have obvious advantages in electronic conductivity. A carbon-based matrix may not only improve the electrical conductivity of the carbon/sulfur cathode, but can also reduce the loss of the intermediate products-soluble polysulfides by physical adsorption [108-110]. Metal oxide and metal sulfide having a strong chemical adsorption polysulfide can effectively reduce the loss of active substance, which can improve the cycle performance of LSBs [111-113]. However, since the metal oxide/sulfide itself has poor conductivity, it is often combined with a carbon-based material to improve the performance of LSBs. Black phosphorus has advantages of both formers, such as high electronic conductivity, fast lithium-ion diffusion, and adsorption and catalytic conversion for polysulfides [114-116]. At the same time, the bonding energy between $\mathrm{P}$ and $\mathrm{S}$ is $285-442 \mathrm{~kJ} / \mathrm{mol}$, which is less than the P-P bond $(485 \mathrm{~kJ} /$ mol) [114], indicating that the combination of phosphorus and polysulfide cannot destroy the bulk structure of black phosphorus. To date, there have been some reports about the application of black phosphorus in LSBs, which can act as a carrier on the cathode side and the modified layer on the separator.

\section{Modification of a Sulfur Cathode}

The modification of a sulfur cathode requires a host material that has good electronic conductivity and sulfur adsorption. Considering this aspect, the host materials for sulfur improve the conductivity, but also trap and reactivate the dissolved polysulfides. At present, the modification of a sulfur positive electrode using the black phosphorus-carbon composite material as a host material 
Table 1 Overview of the studies on black phosphorus-based anode materials for LIBs and SIBs

\begin{tabular}{|c|c|c|c|c|c|}
\hline Material & Preparation method & $\mathrm{P}(\mathrm{wt} . \%)$ & Battery type & Cycle performance & Ref \\
\hline $\mathrm{BP} /$ super P & Ball-milling & 70 & LIBs & $600 \mathrm{mAh} / \mathrm{g}(100 \text { cycles, } 0.78-2 \mathrm{~V})^{\mathrm{a}}$ & {$[53]$} \\
\hline BP-G & Ball-milling & 25 & LIBs & $\begin{array}{l}1849 \mathrm{mAh} / \mathrm{g}(\text { after } 100 \text { cycles at } \\
520 \mathrm{~mA} / \mathrm{g})^{\mathrm{a}}\end{array}$ & {$[67]$} \\
\hline $\mathrm{P}-\mathrm{KB}$ & Ball-milling & 70 & LIBs & $\begin{array}{l}1000 \mathrm{mAh} / \mathrm{g}(\text { after } 300 \text { cycles at } 1 \\
\mathrm{A} / \mathrm{g})^{\mathrm{b}}\end{array}$ & {$[68]$} \\
\hline P-CNT hybrid & Ball-milling & 70 & LIBs & $\begin{array}{l}1844 \mathrm{mAh} / \mathrm{g}(\text { after } 300 \text { cycles at } \\
780 \mathrm{~mA} / \mathrm{g})^{\mathrm{a}}\end{array}$ & [69] \\
\hline $\mathrm{BPC}$ & Ball-milling & 70 & SIBs & $\begin{array}{l}1700 \mathrm{mAh} / \mathrm{g}(\text { after } 100 \text { cycles at } 1.3 \\
\mathrm{A} / \mathrm{g})^{\mathrm{a}}\end{array}$ & {$[70]$} \\
\hline MWCNTs@f-RP@BP & $\begin{array}{l}\text { Mineralizer-assisted vapor phase } \\
\text { method }\end{array}$ & 46 & LIBs & $\begin{array}{l}561 \mathrm{mAh} / \mathrm{g} \text { (after } 200 \text { cycles at } \\
500 \mathrm{~mA} / \mathrm{g})^{\mathrm{b}}\end{array}$ & [71] \\
\hline BP-CNTs & $\begin{array}{l}\text { Surface oxidation-assisted chemical } \\
\text { bonding procedure }\end{array}$ & 70 & LIBs and SIBs & $\begin{array}{l}1177 \mathrm{mAh} / \mathrm{g} \text { (after } 400 \text { cycles } \\
\text { at } 520 \mathrm{~mA} / \mathrm{g} \text { for LIBs) }{ }^{\mathrm{b}} \text { and } \\
1092 \mathrm{mAh} / \mathrm{g}(\text { after } 200 \text { cycles at } \\
520 \mathrm{~mA} / \mathrm{g} \text { for SIBs) })^{\mathrm{b}}\end{array}$ & [72] \\
\hline Phosphorus-based nanosheets & Wet-chemical solvothermal reaction & 100 & LIBs & $\begin{array}{l}1683 \mathrm{mAh} / \mathrm{g}(\text { after } 100 \text { cycles at } \\
200 \mathrm{mAh} / \mathrm{g})^{\mathrm{a}}\end{array}$ & {$[78]$} \\
\hline Black phosphorus@graphene film & $\begin{array}{l}\text { Mineralizer-assisted gas-phase trans- } \\
\text { formation and vacuum filtration }\end{array}$ & 80 & LIBs & $\begin{array}{l}402 \mathrm{mAh} / \mathrm{g}(\text { after } 500 \text { cycles at } \\
500 \mathrm{mAh} / \mathrm{g})^{\mathrm{b}}\end{array}$ & [79] \\
\hline Phosphorene@graphene hybrid & Liquid-phase exfoliation & 48.3 & SIBs & $\begin{array}{l}2080 \mathrm{mAh} / \mathrm{g}(\text { after } 100 \text { cycles at } \\
50 \mathrm{~mA} / \mathrm{g})^{\mathrm{a}}\end{array}$ & {$[65]$} \\
\hline Phosphorene/graphene hybrid & $\begin{array}{l}\text { Electrochemical exfoliation and } \\
\text { solvothermal method }\end{array}$ & 51.05 & SIBs & $\begin{array}{l}1582 \mathrm{mAh} / \mathrm{g}(\text { after } 200 \text { cycles at } 1 \\
\mathrm{A} / \mathrm{g})^{\mathrm{a}}\end{array}$ & {$[80]$} \\
\hline Layered BP@graphene & Pressurization at room temperature & 78.3 & SIBs & $\begin{array}{l}\sim 1250 \mathrm{mAh} / \mathrm{g}(\text { after } 500 \text { cycles at } \\
1 \mathrm{~A} / \mathrm{g})^{\mathrm{a}}\end{array}$ & {$[81]$} \\
\hline BP-G/PANI & Sonication and coating & 65 & SIBs & $\begin{array}{l}520 \mathrm{mAh} / \mathrm{g} \text { (after } 1000 \text { cycles at } 4 \\
\mathrm{~A} / \mathrm{g})^{\mathrm{b}}\end{array}$ & {$[82]$} \\
\hline $\mathrm{BP} / \mathrm{TiO}_{2}$ /graphene & $\begin{array}{l}\text { Hydrothermal reaction and liquid } \\
\text { exfoliation }\end{array}$ & - & LIBs & $\begin{array}{l}502 \mathrm{mAh} / \mathrm{g} \text { (after } 180 \text { cycles at } 1.25 \\
\mathrm{~A} / \mathrm{g})^{\mathrm{b}}\end{array}$ & [83] \\
\hline $\mathrm{BPQD} / \mathrm{TNS}$ & Sonication and stirring & 12 & LIBs and SIBs & $\begin{array}{l}520 \mathrm{mAh} / \mathrm{g} \text { (after } 2400 \text { cycles at } 1 \\
\mathrm{~A} / \mathrm{g} \text { for LIBs) }{ }^{\mathrm{b}} \text { and initial discharge } \\
\text { capacity of } \sim 723 \mathrm{mAh} / \mathrm{g} \text { for SIBs }{ }^{\mathrm{b}}\end{array}$ & [84] \\
\hline
\end{tabular}

${ }^{\mathrm{a}}$ The capacity was calculated based on the weight of phosphorus

${ }^{\mathrm{b}}$ The capacity was calculated based on the total weight of the phosphorus/carbon composite

can meet the above requirements. In 2017, Li et al. [115] combined a small layer of black phosphorus (FLP) with porous carbon nanofibers (CNF) to product a black phosphorus/CNF hybrid host material, in which a black phosphorus nanosheet is well dispersed onto CNFs (Fig. 9a). Black phosphorus has a strong chemical adsorption on both polysulfide and $\mathrm{Li}_{2} \mathrm{~S}$, which can inhibit the loss of sulfur. The CNF network provides a good electron path. Therefore, the combination of the two functional materials has very good synergy. The specific capacity of the sulfur cathode maintained $660 \mathrm{mAh} / \mathrm{g}$ after 500 cycles (a single-cycle capacity fade only $0.053 \%$ ), significantly better than the electrode using only pure CNF as a host (Fig. 9b).

\section{Modification of a Separator}

The performance of LSBs can be improved by modifying the polymer separator of LSBs to block the diffusion of polysulfide molecules, thereby improving the utilization efficiency of sulfur. A surface-modified membrane using a coating layer to prevent migration of the lithium polysulfide, thereby suppressing the occurrence of "shuttle" effect, can effectively improve the rate and cycle performance of the battery. Sun et al. [114] reported a modification in 2016 by coating black phosphorus nanosheets on the surface of commercial polyethylene separators (Fig. 9c). Due to the physical adsorption and chemisorption of black phosphorus, both the intermediate polysulfide and solid $\mathrm{Li}_{2} \mathrm{~S}_{2}$ and $\mathrm{Li}_{2} \mathrm{~S}$ have strong binding energy (from -1.86 to $-3.05 \mathrm{eV}$ ) (Fig. 9d). In the electrochemical performance testing, the performance of the blackphosphorus-modified membrane was significantly better than 
(a)

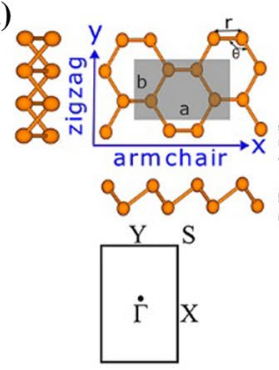

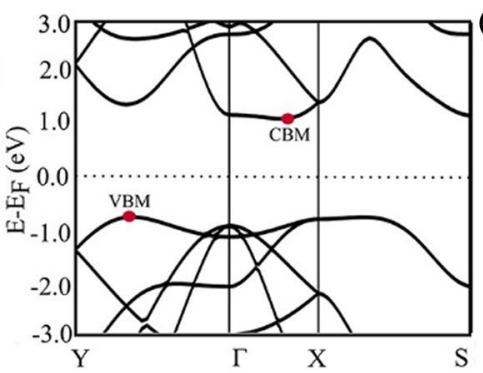

(b)

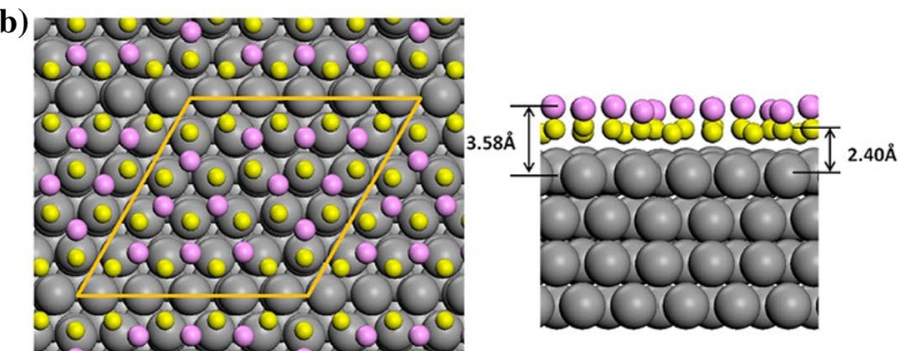

(c)

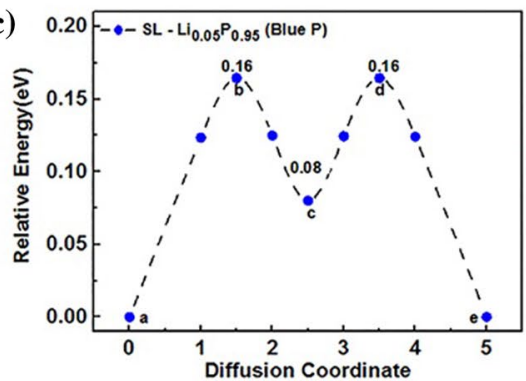

(e)

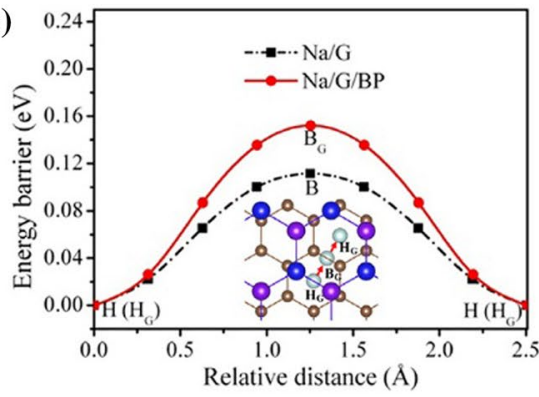

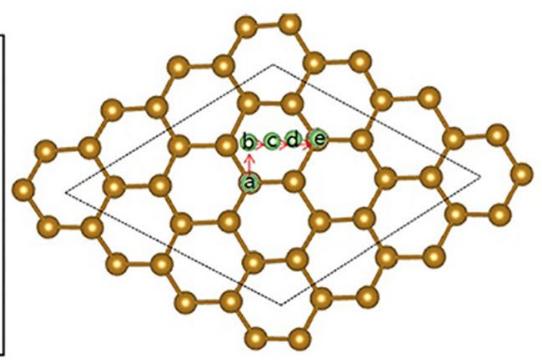

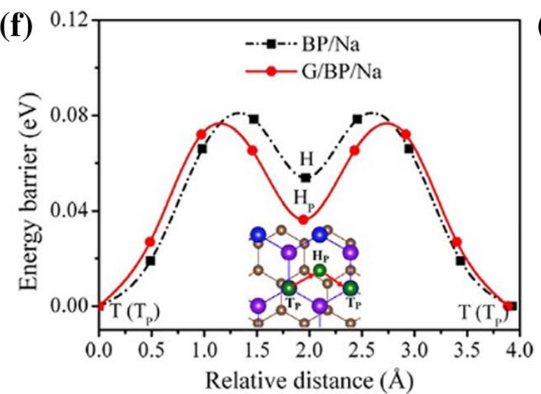

(d)
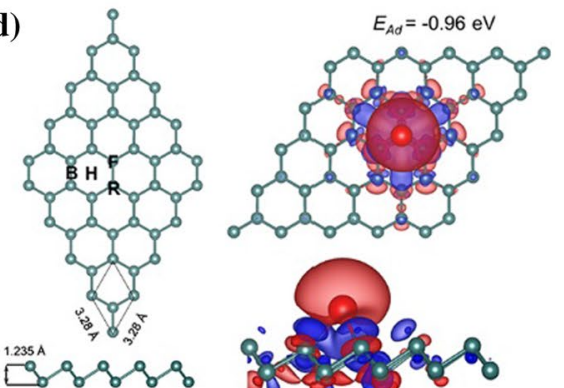

(g)

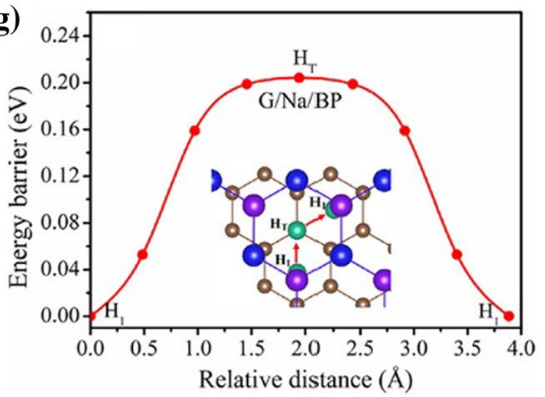

Fig. 6 a Top and side views of monolayer blue phosphorus and the electronic band structure along various high symmetry directions [89]; b DFT results for single-layer blue phosphorus on $\mathrm{Au}(111)$. The top (bottom) phosphorus atoms are represented as purple (yellow) balls, while the Au atoms are represented as gray balls [49]. c Sche- matic representations and potential-energy curves of Li diffusion on blue phosphorus [90]; $\mathbf{d}$ top and side views of charge density difference plots for the most stable adsorption sites for $\mathrm{Na}$ [91]; diffusion paths of $\mathrm{Na}$ on the e graphene side; $\mathbf{f}$ black phosphorus side; and $\mathbf{g}$ interlayer of blue phosphorus/graphene heterostructure [92] that of the graphene-modified membrane. At a current density of $400 \mathrm{~mA} / \mathrm{g}$, the discharge capacity per cycle was $800 \mathrm{mAh} / \mathrm{g}$ and the retention rate was as high as $86 \%$.

Using extensive DFT calculations, Mukherjee et al. [117] demonstrated that blue phosphorus (rP) is also well suited as a cathode for LSBs. As shown in Fig. 9e, the interaction strength of $\mathrm{S}_{8}$ and the polysulfides are reasonably strong (from -0.86 to $-2.45 \mathrm{eV}$ ) compared to pristine blue phosphorus. Furthermore, introducing a single vacancy increased the adsorption energy by up to $200 \%$.

\section{Lithium-Air Battery}

A LAB is an electrochemical device of a metal anode and air cathode using mainly oxygen in the air to produce catalytic energy. Due to its very high energy density $(\sim 3500 \mathrm{Wh} / \mathrm{kg})$ and availability of oxygen as a raw material, this battery is considered to be a potentially efficient energy candidate $[118,119]$. LABs have been proposed and developed as four types: aprotic (non-aqueous, Fig. 10a), aqueous (Fig. 10b), solid-state (Fig. 10c) and mixed aqueous/aprotic (Fig. 10d) [120], which is based on the classification of internal battery electrolytes. The most mature lithium-air battery is the non-aqueous system (Fig. 10e) [121], which involves lithium dissolution and deposition on the lithium electrode and ORR and OER on the air electrode. Although the non-aqueous LABs can hold much more storage space than LIBs, there are still some challenges for their practical applications, including instability after high-frequency service, poor rate capability, cycle life, and safety hazards derived from the formation of lithium dendrites [122-125].

Nanoblack phosphorus of a certain mechanical strength can be applied as a protective layer of the LAB anode, and 
Fig. 7 a Scanning electron microscope (SEM) image of the black phosphorus/graphite composite [99]; b cycling performance of the black phosphorus/ graphite composite at $50 \mathrm{~mA} / \mathrm{g}$ [99]; $\mathbf{c}$ schematic diagram of the a-P/C composite [100]; $\mathbf{d}$ cycling stability of the a-P/C anode at $50 \mathrm{~mA} / \mathrm{g}$ [100]
Fig. 8 Schematic and energy profiles of $\mathrm{Mg}$ diffusion along a, c, e the zigzag direction and $\mathbf{b}, \mathbf{d}, \mathbf{f}$ armchair direction on the phosphorene surface [103]
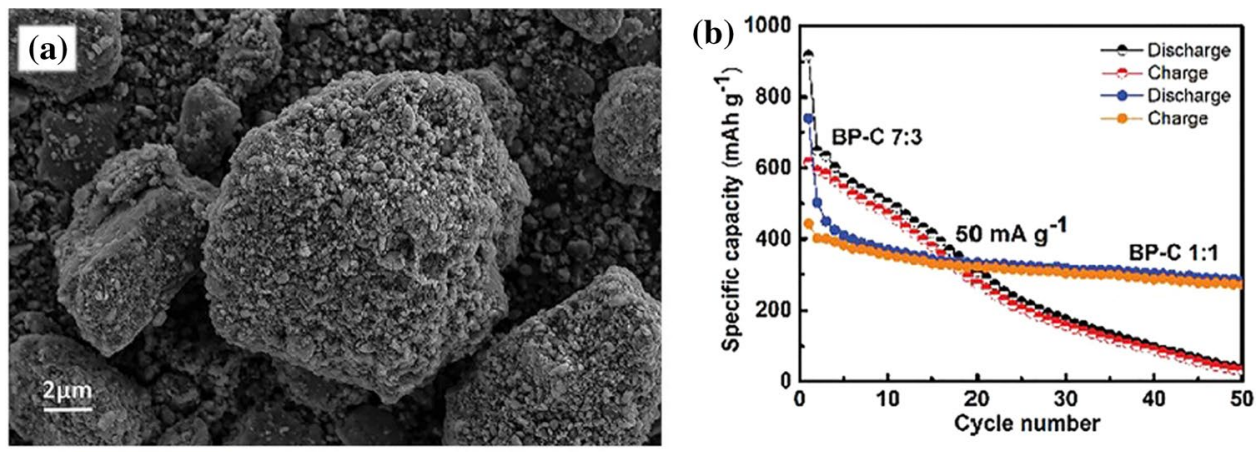

(c)

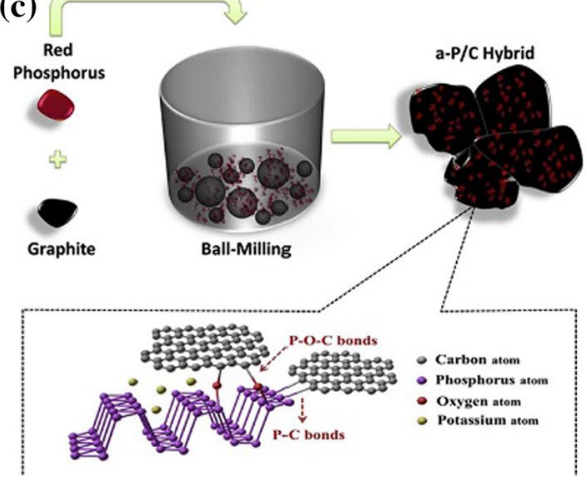

(a)
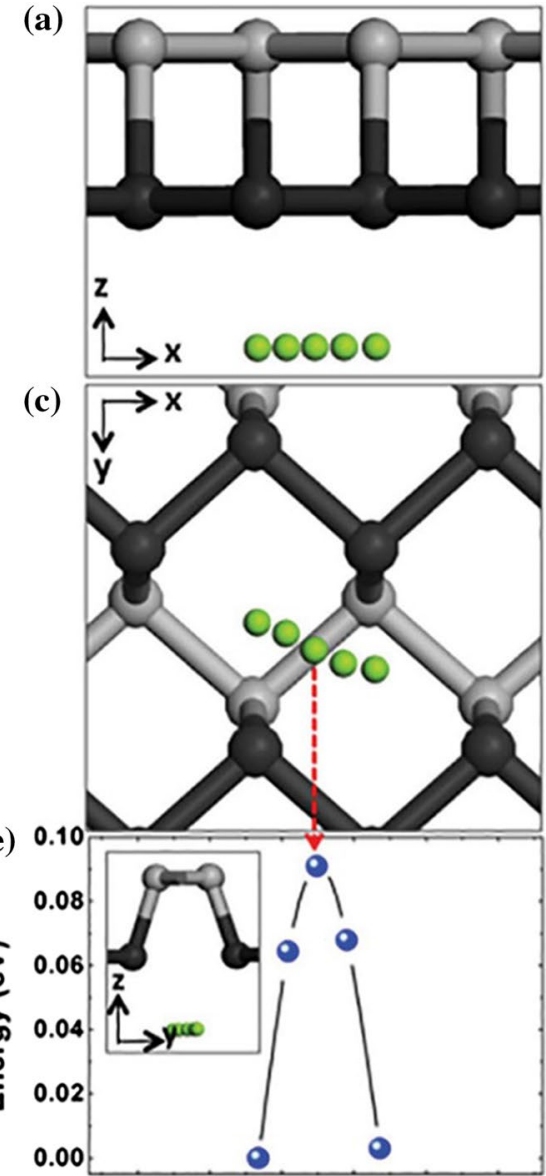

Diffusion Co-ordinate (d)

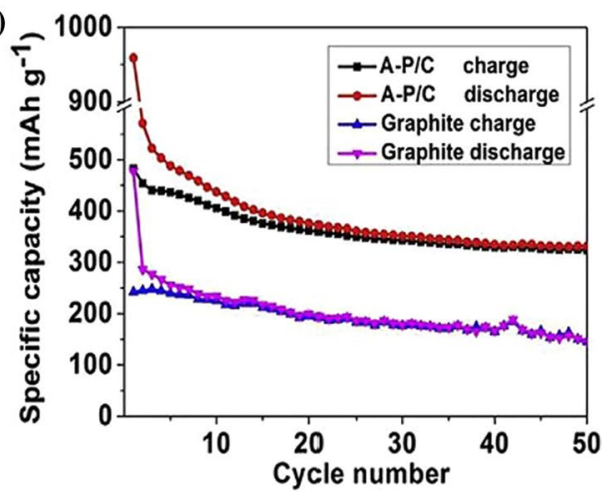

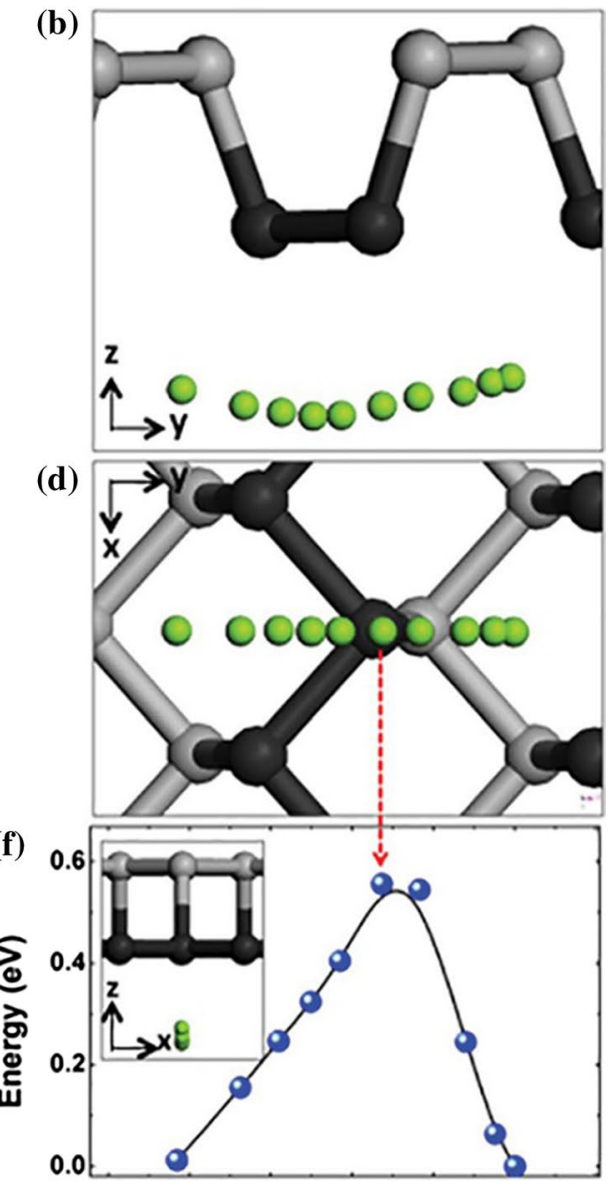

Diffusion Co-ordinate 

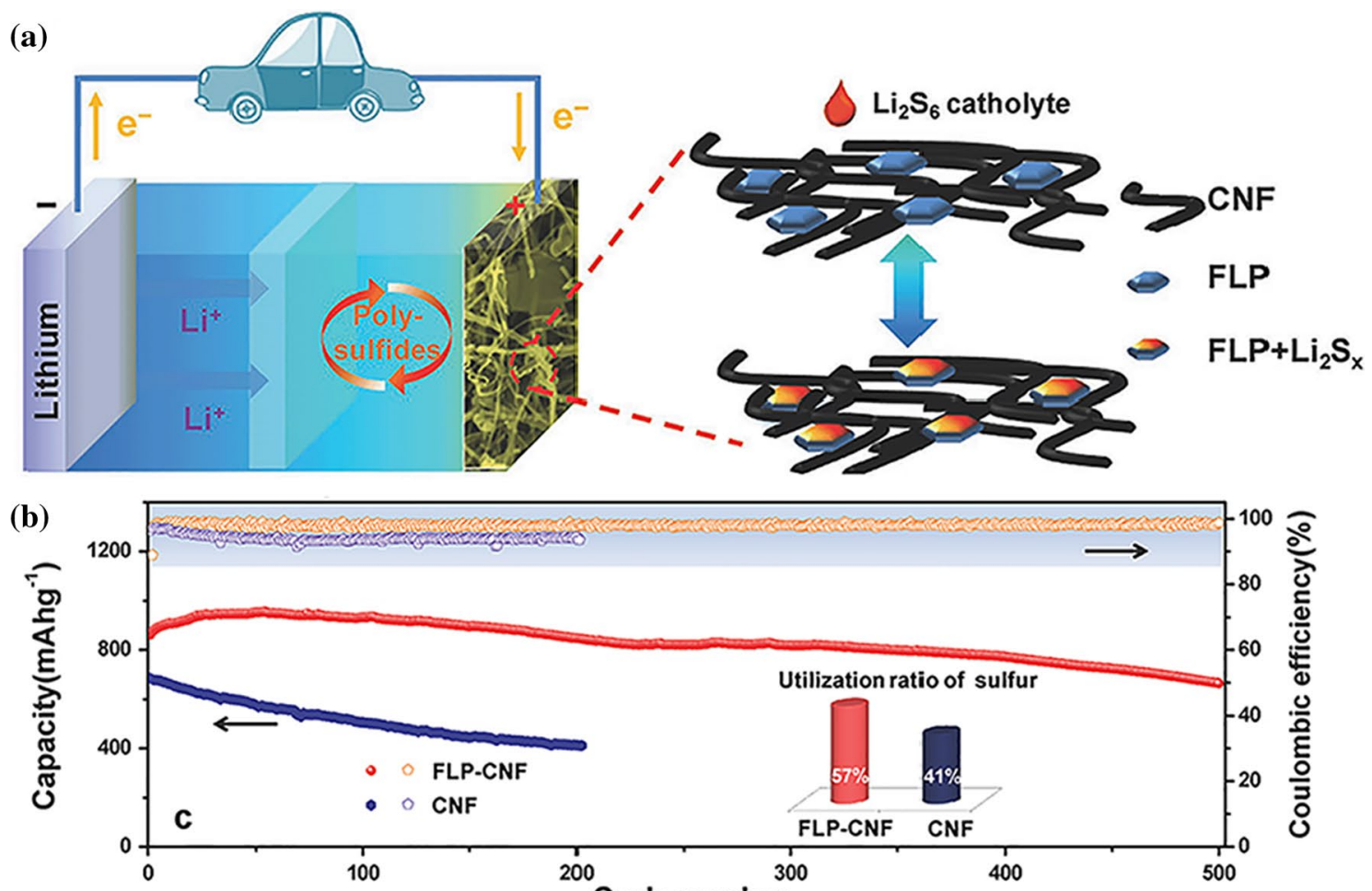

(c)
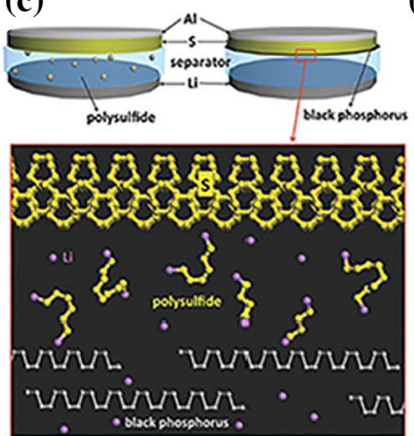

(e)

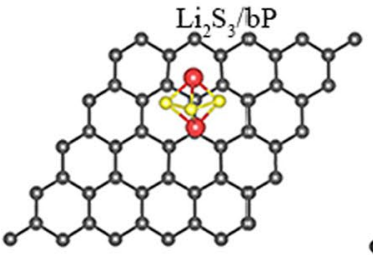

(d)

Cycle number
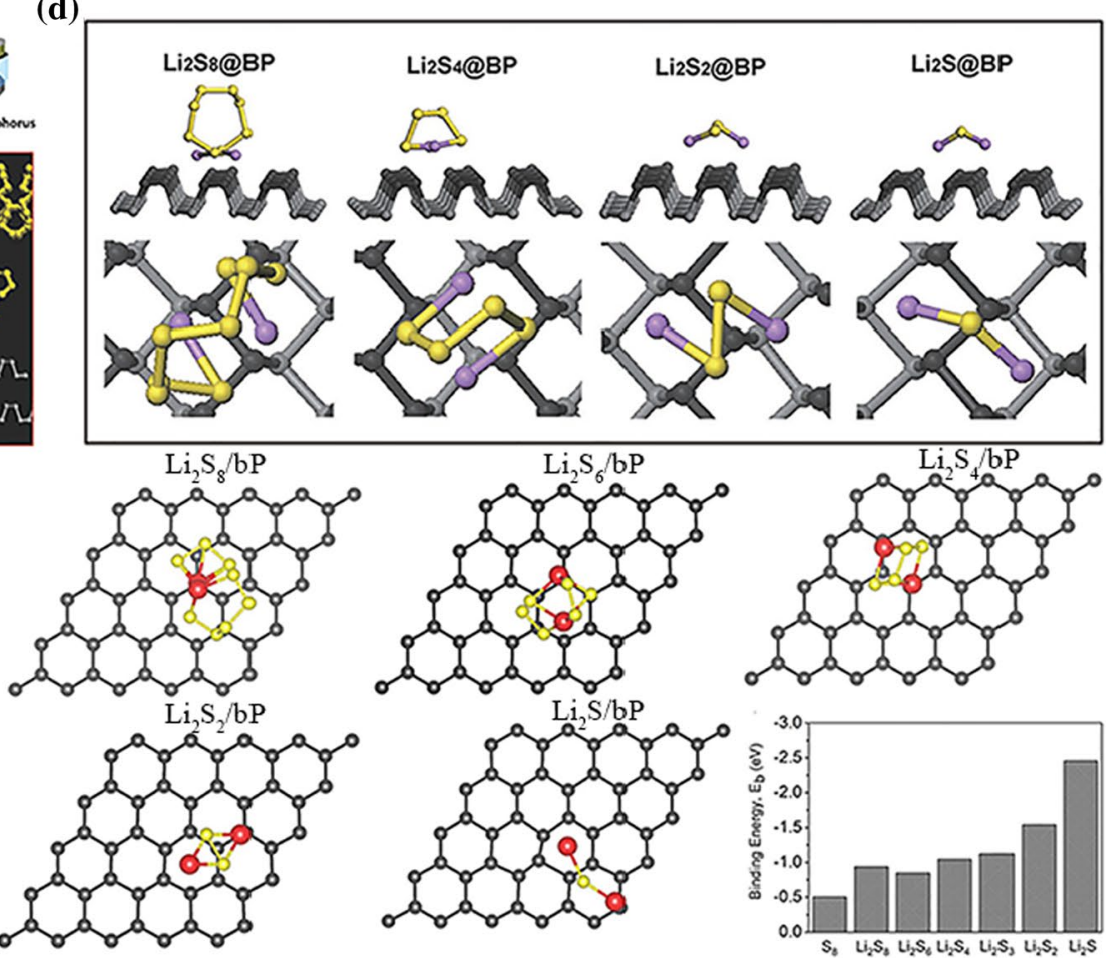

Fig. 9 a Schematic of black phosphorus/carbon nanotubes capturing polysulfides [115]; b cycle stability performance and Coulombic efficiency of black phosphorus/carbon nanotubes [115]; c working principle of black phosphorus modified membrane [114]; $\mathbf{d}$ the adsorp- tion sites for $\mathrm{Li}_{2} \mathrm{~S}_{8}, \mathrm{Li}_{2} \mathrm{~S}_{4}, \mathrm{Li}_{2} \mathrm{~S}_{2}$, and $\mathrm{Li}_{2} \mathrm{~S}$ on black phosphorus [114]; e the adsorption sites of $\mathrm{S}_{8}, \mathrm{Li}_{2} \mathrm{~S}_{8}, \mathrm{Li}_{2} \mathrm{~S}_{6}, \mathrm{Li}_{2} \mathrm{~S}_{4}, \mathrm{Li}_{2} \mathrm{~S}_{3}, \mathrm{Li}_{2} \mathrm{~S}_{2}$, and $\mathrm{Li}_{2} \mathrm{~S}$ systems over monolayer pristine blue phosphorus (rP) and the corresponding binding energies [117] 
an alloying reaction between the lithium metal and black phosphorus may occur, resulting in forming $\mathrm{Li}_{3} \mathrm{P}$ layers [122]. Additionally, the redox potential of black phosphorus converting into $\mathrm{Li}_{3} \mathrm{P}\left(\sim 0.9 \mathrm{~V}\right.$ vs $\left.\mathrm{Li}_{/} / \mathrm{Li}^{+}\right)$is greater than the LUMO level of the electrolyte $\left(<0.8 \mathrm{~V}\right.$ vs $\left.\mathrm{Li} / \mathrm{Li}^{+}\right)$, thus suppressing electrolyte decomposition (Fig. 10f). Researchers have studied the possibility of applying black phosphorus nanolayers to the LAB. The surface of the lithium electrode was coated with a black phosphorus layer and then circulated with a capacity of $1000 \mathrm{mAh} / \mathrm{g}$ using $1 \mathrm{~mol} / \mathrm{L}$ lithium bis(trifluoromethanesulfonyl) imide in N,N-dimethylacetamide. The electrochemical performance of the Li metal anode with the black phosphorus coating was tested for 50 cycles without significant attenuation capacity, indicating the application of such black phosphorus in the cell may be possible.

In non-aqueous LABs, the discharge and charge processes are based on the reaction of $2 \mathrm{Li}^{+}+\mathrm{O}_{2} \leftrightarrow \mathrm{Li}_{2} \mathrm{O}_{2}$, where $\mathrm{Li}_{2} \mathrm{O}_{2}$ forms as the main discharge product at the cathode [126-128]. Unlike the Li-ion intercalation mechanism in LIBs, the intrinsically insulating/insoluble nature of $\mathrm{Li}_{2} \mathrm{O}_{2}$ in non-aqueous organic electrolyte, as well as the side reactions between the electrolyte and $\mathrm{Li}_{2} \mathrm{O}_{2}$, will introduce the reduced ORR/OER kinetics, which leads to high overpotential, inferior cycling stability and poor rate capability $[127,129]$. One of the solutions is to rationally design an advanced catalytic cathode to promote the formation/ decomposition of $\mathrm{Li}_{2} \mathrm{O}_{2}$ and suppress the formation of other lithium compounds (such as $\mathrm{Li}_{2} \mathrm{CO}_{3}$ and $\mathrm{LiOH}$ ) [130, 131]. Cheng et al. [127] designed a black phosphorus quantum dots-decorated $\mathrm{MnO}_{2}\left(\mathrm{BPQD} / \mathrm{MnO}_{2}\right)$ catalyst, which was grown on carbon cloth as a binder-free cathode for LABs. In this catalyst, the presence of BPQDs can enhance the electrode conductivity and improve the catalytic activity for ORR/OER. The cycling performance of the $\mathrm{BPQD} / \mathrm{MnO}_{2}$ and $\mathrm{MnO}_{2}$-catalyzed LAB was evaluated by galvanostatic cycling at $400 \mathrm{~mA} / \mathrm{g}$ at $2.0-4.5 \mathrm{~V}$ with a limited capacity of $1000 \mathrm{mAh} / \mathrm{g}$. As shown in Fig. $10 \mathrm{~g}$, the $\mathrm{BPQD} / \mathrm{MnO}_{2}-$ catalyzed cell maintained stable cycling for 182 cycles but only 22 cycles for the $\mathrm{MnO}_{2}$-catalyzed cell. By the DFT, the adsorption energy of $\mathrm{LiO}_{2}$ on bare $\mathrm{MnO}_{2}$ is $2.589 \mathrm{eV}$, while that on $\mathrm{BPQD} / \mathrm{MnO}_{2}$ is $3.557 \mathrm{eV}$, indicating that $\mathrm{BPQD}$ plays a key role in directing the conformal growth of $\mathrm{Li}_{2} \mathrm{O}_{2}$ on the surface of $\mathrm{MnO}_{2}$.

Very recently, N-doped blue phosphorus was also demonstrated to be a promising catalytic material in the cathode of LABs by DFT calculations based on the following characteristics [132]. (1) The blue phosphorus monolayer was stable during adsorption in the lithium-ion processes, contributing to sustaining a long-term electrochemical stability. (2) The low barrier energy of $0.11 \mathrm{eV}$ along path 4 in Fig. 10h (right) indicates that $\mathrm{Li}$ can easy diffuse on the nitrogen-doped blue phosphorus surface. (3) The final product $\mathrm{Li}_{2} \mathrm{O}_{2}$ is more likely to form via the reaction pathway in Fig. 10i (right) on the $\mathrm{N}$-doped blue phosphorus than that of the pristine blue phosphorus (left, Fig. 10i). (4) The N-doped blue phosphorus maintains the indirect semiconductor characteristic with a band gap of $\sim 0.92 \mathrm{eV}$, lower than pristine blue phosphorus $(1.95 \mathrm{eV})$, illustrating that the conductivity of $\mathrm{N}$-doped blue phosphorus is enhanced.

\section{Supercapacitor}

A supercapacitor is a battery-complementary device for applications in high operating power levels, with characteristics of fast (dis)charging, and the high-energy storage characteristics. Therefore, it has prospects in the application of electrochemistry. However, among the allotropes of phosphorus, only two-dimensional black phosphorus materials have been reported in the application of supercapacitors [133-139].

In 2016, Hao et al. [135] reported a method for preparing black phosphorus film electrodes by dispersing black phosphorus nanoflakes in acetone on a platinum/polybutylene terephthalate (PET) substrate. Subsequently, they sandwiched the polyvinyl alcohol/phosphoric acid (PVA/ $\mathrm{H}_{3} \mathrm{PO}_{4}$ ) between two as-prepared black phosphorus films on Pt-coated PET to develop a device based on an electrical double-layer capacitor (Fig. 11a). At the $0.5 \mathrm{~V} / \mathrm{s}$ sweep speed, the capacity retention rate reached $84.5 \%$ after 10,000 cycles. After 30,000 cycles in flat and bent alternating configuration, a capacity retention rate of $71.8 \%$ was maintained (Fig. 11b). Very recently, a similar approach was used to design an all-solid-state supercapacitor constructed with a semi-connected 3D black phosphorus sponge comprised of thin black phosphorus nanosheets, named BP sponge-ASSP (Fig. 11c) [136]. The difference is that this nanosheet is thinner (less than $4.0 \mathrm{~nm}$ ). As shown in Fig. 11d, the CV curves at $10-100 \mathrm{mV} / \mathrm{s}$ show characteristic rectangular electrochemical double-layer capacitance curves. The corresponding capacitances at the different scanning rates are shown in Fig. 11e. The BP sponge-ASSP showed a specific capacitance of $80 \mathrm{~F} / \mathrm{g}$ at $10 \mathrm{mV} / \mathrm{s}$ and retained the capacitance of $28 \mathrm{~F} / \mathrm{g}$ when the scanning rate increased to $100 \mathrm{mV} / \mathrm{s}$.

In 2017, Yang et al. [137] reported the idea of assembling laminated composite films to prepare flexible electrodes for supercapacitors. They used black phosphorus and carbon nanotubes to prepare the composite electrode, in which the carbon nanotubes delivered high conductivity and prevented the black phosphorus sheets from re-stacking. A flexible allsolid supercapacitor made with a mass ratio of black phosphorus to carbon nanotubes of 1:4 provides a maximum volume capacitance of $41.1 \mathrm{~F} / \mathrm{cm}^{3}$ at a sweep rate of $0.005 \mathrm{~V} / \mathrm{s}$. This result was superior to the solid capacitors based on bare graphene or black phosphorus. Moreover, it has excellent mechanical flexibility and high cycle stability of more 

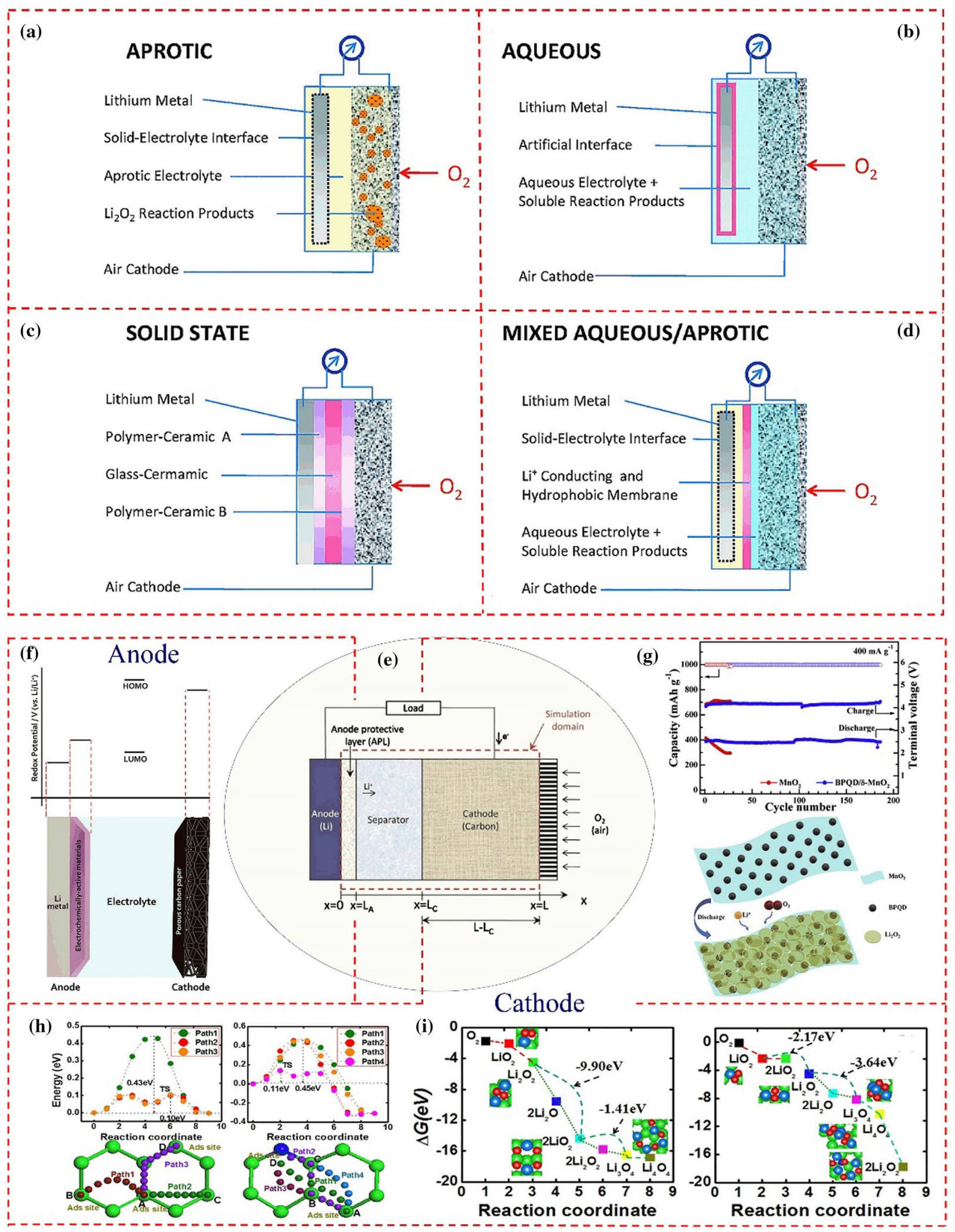

Fig. 10 Four different architectures of LABs: a non-aqueous; $\mathbf{b}$ aqueous; c solid-state and $\mathbf{d}$ mixed aqueous/non-aqueous [120]. e A schematic representation of a non-aqueous LABs [121]; f schematic diagram of the electrochemically active protective layer concept [122]; g cycling performance with different cathodes and formation mecha- nism of $\mathrm{Li}_{2} \mathrm{O}_{2}$ on $\mathrm{BPQD} / \mathrm{MnO}_{2}$ [127]; $\mathbf{h}$ possible pathways and corresponding energy barriers for the diffusion of a lithium on pristine (left) and $\mathrm{N}$-doped (right) blue phosphorus [132]; i the energetic profile of the reduction of a lithium oxide $\left(\mathrm{Li}_{x} \mathrm{O}_{y}\right)$ molecule on a pristine (left) and N-doped (right) blue phosphorus [132] 
than 10,000 cycles, with $91.5 \%$ capacity after cycling. Since polypyrrole (PPy) has a high chemical activity and good flexibility, Luo et al. [138] reported a method for preparing a laminated PPy/black phosphorus film via an electrochemical polymerization method. The introduction of black phosphorus sheets solved the inherent defects of the pure PPy such as the low capacitance and poor cycle stability. The composite film has a high capacitance of $551.7 \mathrm{~F} / \mathrm{cm}^{3}$ and excellent cycle stability due to the black phosphorus sheet-induced laminate assembly that hinders the dense and disorderly stacking of PPy during electrodeposition. Thus, it provided an accurate path for both ion diffusion and electron transport and also mitigated structural degradation during charge/ discharge. In order to improve the stability of black phosphorus in air, a black phosphorus heterostructured material was designed by chemically modifying black phosphorus on the surface of carbon nanotubes with 4-nitrobenzene diazonium (4-NBD), named BP-CNTs/4-NBD (Fig. 12a) [139]. Furthermore, to make the materials flexible and wearable, Wu et al. [139] assembled the BP-CNTs/4-NBD into nonwoven fiber fabrics using a microfluidic spinning technique (MST). As shown in Fig. 12b, in order to improve the volume density, the fabrics were mechanically compressed into free-standing films with various shapes. Subsequently, two fabric film layers laminated a half-dried poly(vinylidene fluoride-co-hexa fluoropropylene) (PVDF-HFP)/1-ethyl3-methylimidazolium tetrafluoroborate $\left(\mathrm{EMIBF}_{4}\right)$ ion liquid electrolyte layer to construct a flexible supercapacitor (Fig. 12c), exhibiting a high energy density $(96.5 \mathrm{mWh} / \mathrm{cm})$ and large volume capacitance $(308.7 \mathrm{~F} / \mathrm{cm})$. Additionally, it was flexible enough to withstand light-emitting diodes for smart watches and displays.

\section{Summary and Outlook}

In this review, we summarized the research progress and future development of black phosphorus materials in various ion batteries (lithium, sodium, potassium, and magnesium), LSB, LABs, and supercapacitors. Through a summary of the previous studies, we demonstrate that black phosphorus as an electrode material can provide higher specific capacity and ion mobility than graphite. The composite materials based on black phosphorus have great advantages and prospects in applications of energy storage and conversion. More carbon materials have also been used as a conductive substrate to recombine with phosphorus to prepare electrode materials and improve the performance. Considering the synergistic effect of black phosphorus and a carbon matrix, further improvements are also needed such as tailoring the dimensionality and size of black phosphorus to match the carbon matrix. The advantages of black phosphorus as an electrode material are being recognized by more researchers, and more results are on the way.

As an important part of this article, LSBs are mainly aimed at the electric vehicle market. The development of high-capacity battery systems is currently a hot topic in electrochemical research. However, there is a lack of effective and feasible methods for suppressing the formation of lithium dendrites using phosphorus material and related studies are ongoing.

Although the prospects for research bring optimism and motivation, we still have to address the challenges in the development and utilization of black phosphorus materials. First of all, the application of black phosphorus material as an electrode material needs to be conducted at large scale and low cost. Second, serious attention needs to be directed to the stability and storage methods of black phosphorus in air and humidity by finding an applicable encapsulation method that preserves its pristine properties in the long term. Third, although a lot of work has been focused on the optimization of black phosphorus and its composite, the electrochemical mechanism of black phosphorus needs to be further studied. The stepwise alloying/dealloying process for a black phosphorus electrode is still not fully understood and intermediates generated in (dis)charging process remain to be investigated. It is necessary to reveal the mechanism of the black phosphorus anode via advanced in situ testing techniques and relevant theoretical calculation. Fourth, the application of black phosphorus as an electrode material is currently focused on the electrode design, and there are few basic research studies on the design of full cells to match with cathodes. The low initial Coulombic efficiency of a phosphorus anode material introduces excessive consumption of $\mathrm{Li}^{+} / \mathrm{Na}^{+} / \mathrm{K}^{+}$with the cathode in full batteries. It is desirable to modify the electrode surface and add an electrolytic additive to reduce the side reactions. Finally, the application of a black phosphorus battery is still in the primary stage, and the safety and environmental protection issues should also be of concern. For example, black phosphorus may release toxic $\mathrm{PH}_{3}$ in the presence of water, posing a safety hazard.

Although there are still many constraints and challenges to be addressed, black phosphorus has a unique structure, with excellent characteristics for research in the energyrelated fields with unlimited possibilities. In the current global context of depleting energy resources, the study of black phosphorus may bring new breakthroughs in the field of energy storage, bringing the discipline to a new stage. We believe that phosphorus, including many black phosphorus-based materials, will contribute to future technological breakthroughs in terms of clean, reliable energy storage. 
Fig. 11 a Schematic illustration for the fabrication of the BP-ASSP devices [135]; b black phosphorus film electrode 30,000 cycles curve [135]; c schematic illustration of the fabrication process of $\mathrm{BP}$ spongeASSP; $\mathbf{d}$ cyclic voltammograms at different scanning rates [136]; e capacitances calculated from the CV curves at different scanning rates [136]

(a)

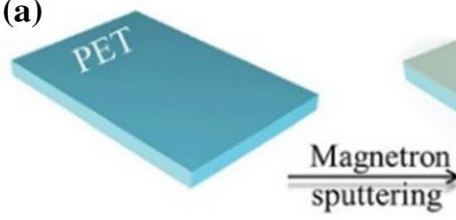

Pt film

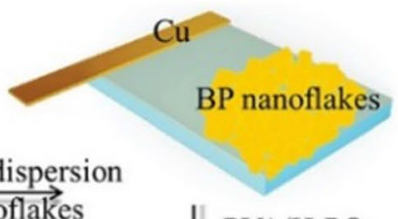
of $\overrightarrow{\text { BP nanoflakes }}$

$\mathrm{PVA} / \mathrm{H}_{3} \mathrm{PO}_{4}$ gel electrolyte
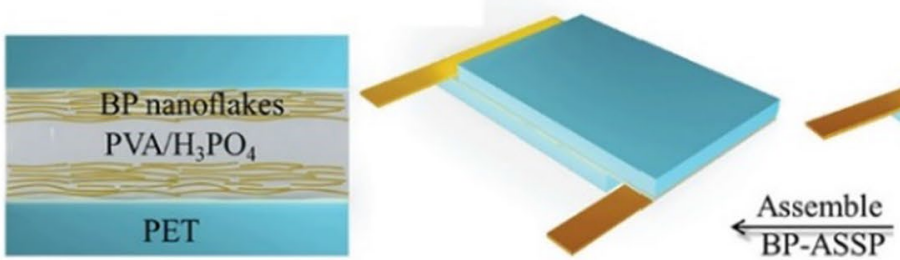

(b) flat bent flat bent flat bent flat bent flat bent

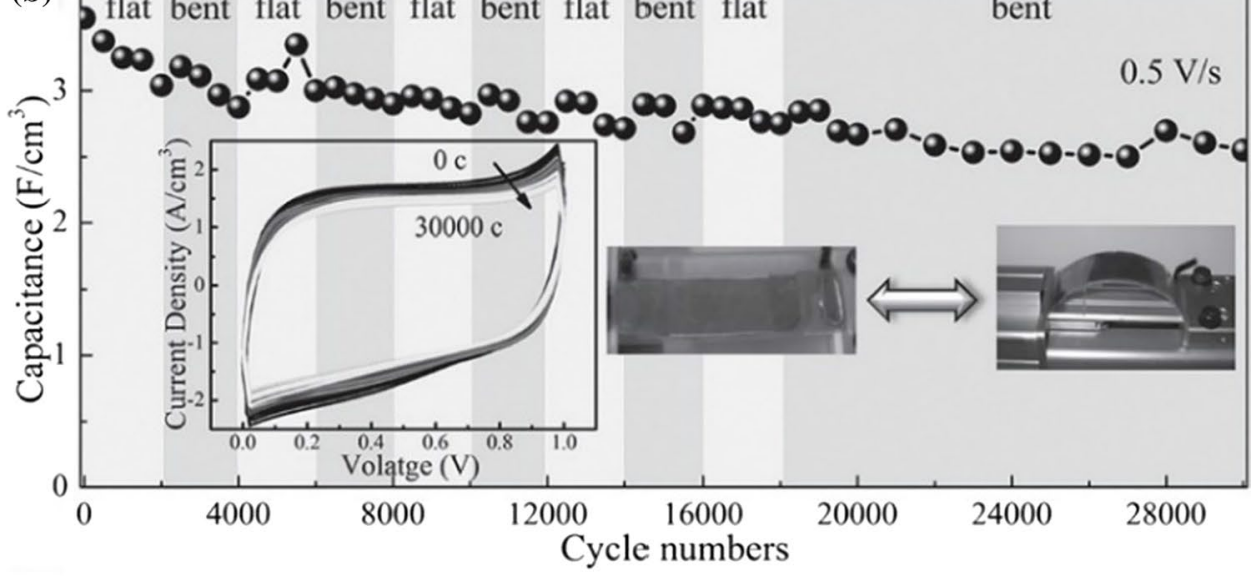

(c)

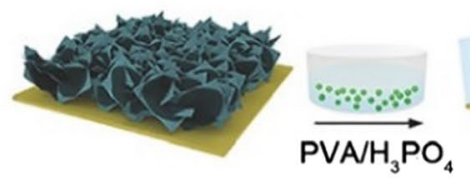

PET/Au/BP

PET/Au/BP/Electrolyte

BP-ASSP

(d)

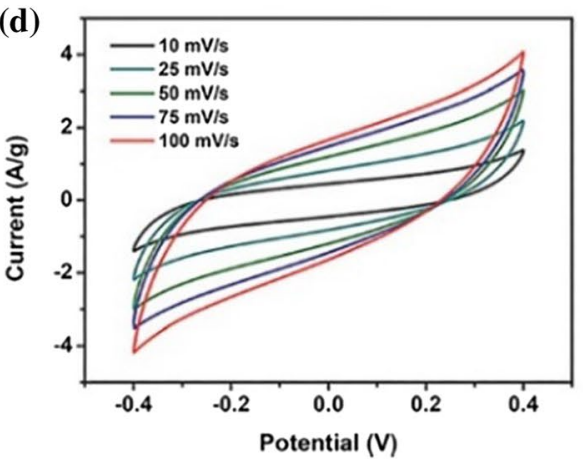

(e)

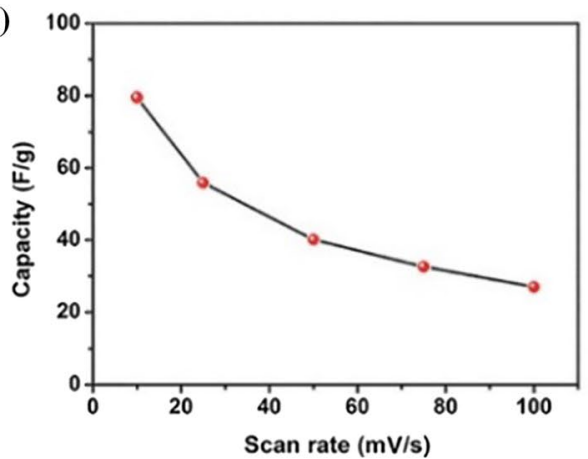


(a) RP

BP-CNTs

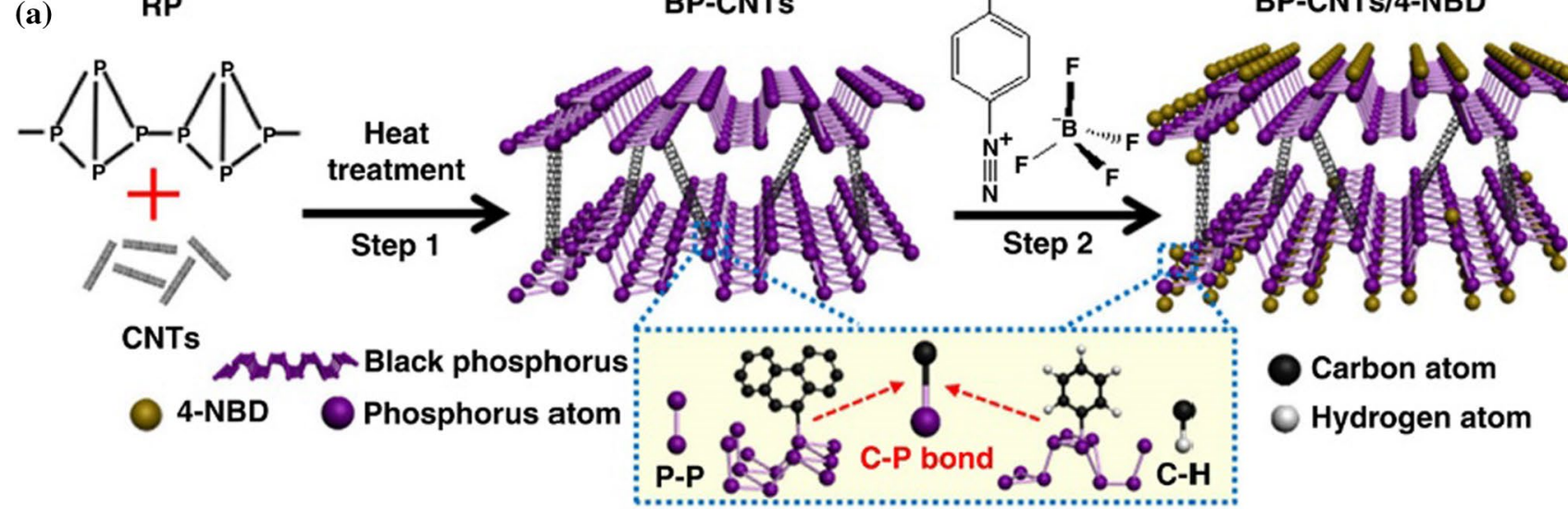

BP-CNTs/4-NBD

(b)

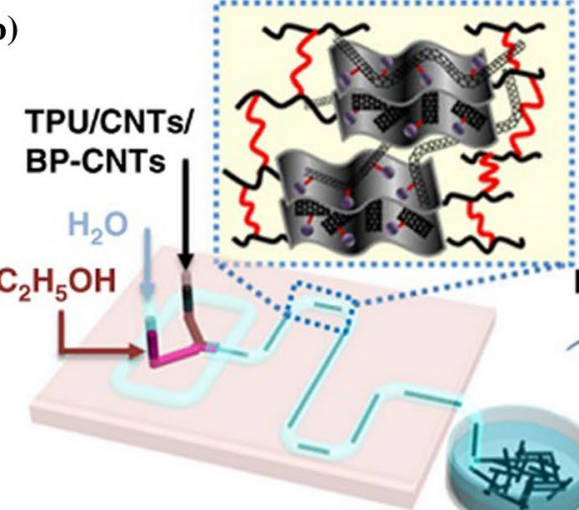

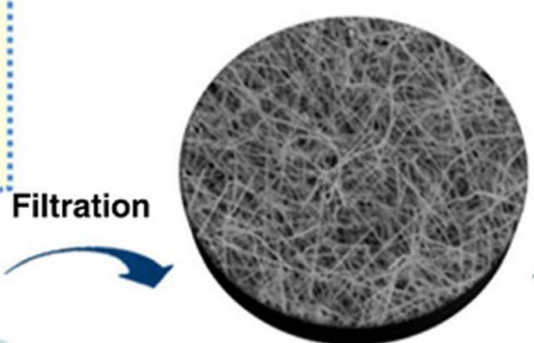

Fibre assembled fabric

Microfluidic spinning

\section{CNTs ma BP-CNTs}

Non-woven fabric
Hot-press

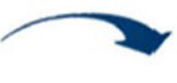

Triangle Pentagram

Conductive film

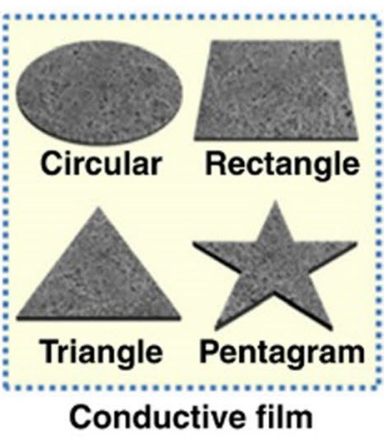

TPU

$-\pi-\pi$ Interaction

(c)
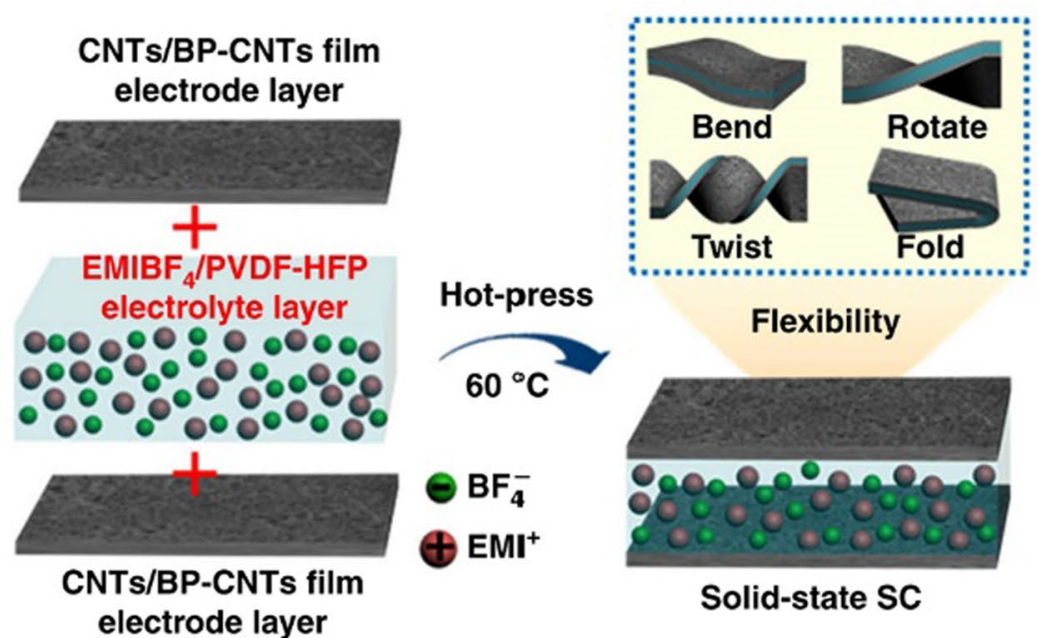

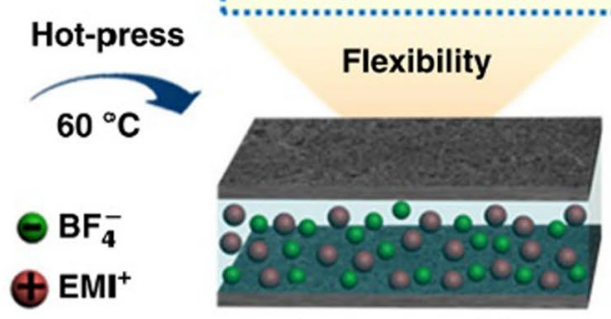

Solid-state SC
Assembly

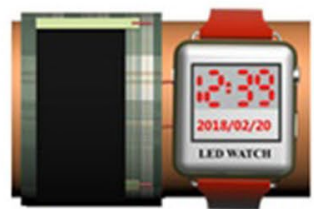

Applications

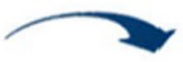

Integration

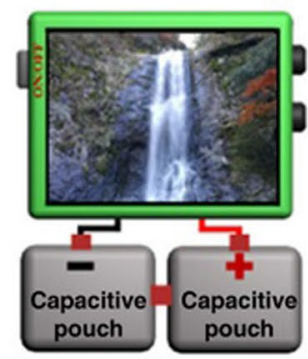

Power electronics

Fig. 12 Schematic illustrations a synthesis of BP-CNTs/4-NBD [139]; b microfluidic spinning technique (MST) fabrication of microfibers [139]; c construction of a flexible supercapacitor and its potential application in various electron devices [139] 
Acknowledgements This work was supported by Tianjin Science and Technology Project (No. 19YFSLQY00070), the Opening Foundation of State Key Laboratory of Organic-Inorganic Composites, Beijing University of Chemical Technology (No. oic-201901004).

Open Access This article is licensed under a Creative Commons Attribution 4.0 International License, which permits use, sharing, adaptation, distribution and reproduction in any medium or format, as long as you give appropriate credit to the original author(s) and the source, provide a link to the Creative Commons licence, and indicate if changes were made. The images or other third party material in this article are included in the article's Creative Commons licence, unless indicated otherwise in a credit line to the material. If material is not included in the article's Creative Commons licence and your intended use is not permitted by statutory regulation or exceeds the permitted use, you will need to obtain permission directly from the copyright holder. To view a copy of this licence, visit http://creativecommons.org/licenses/by/4.0/.

\section{References}

1. Chang B, Kim C, Kim T et al (2015) Demonstration study on the large-scale battery energy storage for renewables integration. Energy Environ 26(1-2):183-194

2. Liu C, Han XP, Cao Y et al (2019) Topological construction of phosphorus and carbon composite and its application in energy storage. Energy Storage Mater 20:343-372

3. Diouf B, Pode R (2015) Potential of lithium-ion batteries in renewable energy. Renew Energy 76:375-380

4. Liu B, Wang XF, Chen HT et al (2013) Hierarchical silicon nanowires-carbon textiles matrix as a binder-free anode for high-performance advanced lithium-ion batteries. Sci Rep 3:1622

5. Guoping W, Qingtang Z, Zuolong Y et al (2008) The effect of different kinds of nano-carbon conductive additives in lithium ion batteries on the resistance and electrochemical behavior of the $\mathrm{LiCoO}_{2}$ composite cathodes. Solid State Ionics 179(7-8):263-268

6. Vaalma C, Buchholz D, Weil M et al (2018) A cost and resource analysis of sodium-ion batteries. Nat Rev Mater 3(4): 18013

7. Kim Y, Ha KH, Oh SM et al (2014) High-capacity anode materials for sodium-ion batteries. Chem Eur J 20(38):11980-11992

8. Martin G, Rentsch L, Höck M et al (2017) Lithium market research—global supply, future demand and price development. Energy Storage Mater 6:171-179

9. Long HW, Zeng W, Wang H et al (2018) Self-assembled biomolecular 1D nanostructures for aqueous sodium-ion battery. Adv Sci 5(3): 1700634

10. Lan DN, Li Q (2019) Manipulating local chemistry of phosphorus for high-performance sodium ion battery anode applications. ACS Appl Energy Mater 2(1):661-667

11. Xie F, Xu Z, Jensen ACS et al (2019) Sodium-ion batteries: hardSoft carbon composite anodes with synergistic sodium storage performance. Adv Funct Mater 29(24):1970164

12. Xiao LF, Lu HY, Fang YJ et al (2018) Low-defect and low-porosity hard carbon with high coulombic efficiency and high capacity for practical sodium ion battery anode. Adv Energy Mater 8(20): 1703238

13. Modarres MH, Lim JHW, George C et al (2017) Evolution of reduced graphene Oxide- $\mathrm{SnS}_{2}$ hybrid nanoparticle electrodes in Li-ion batteries. J Phys Chem C 121(24):13018-13024

14. Li YM, Lu YX, Zhao CL et al (2017) Recent advances of electrode materials for low-cost sodium-ion batteries towards practical application for grid energy storage. Energy Storage Mater 7:130-151

15. Li YM, Hu YS, Titirici MM et al (2016) Hard carbon microtubes made from renewable Cotton as high-performance anode material for sodium-ion batteries. Adv Energy Mater 6(18):1600659

16. Zhang N, Liu Q, Chen WL et al (2018) High capacity hard carbon derived from Lotus stem as anode for sodium ion batteries. J Power Sources 378:331-337

17. Huang SF, Li ZP, Wang B et al (2018) N-doping and defective nanographitic domain coupled hard carbon nanoshells for high performance lithium/sodium storage. Adv Funct Mater 28(10): 1706294

18. Anji Reddy M, Helen M, Groß A et al (2018) Insight into sodium insertion and the storage mechanism in hard carbon. Acs Energy Lett 3(12):2851-2857

19. Xiao LF, Cao YL, Henderson WA et al (2016) Hard carbon nanoparticles as high-capacity, high-stability anodic materials for Naion batteries. Nano Energy 19:279-288

20. Pan KH, Lu HY, Zhong FP et al (2018) Understanding the electrochemical compatibility and reaction mechanism on Na metal and hard carbon anodes of PC-based electrolytes for sodium-ion batteries. ACS Appl Mater Interfaces 10(46):39651-39660

21. Ellis LD, Wilkes BN, Hatchard TD et al (2014) In situ XRD study of silicon, lead and bismuth negative electrodes in nonaqueous sodium cells. J Electrochem Soc 161(3):A416-A421

22. Chen T, Zhao P, Guo X et al (2017) Two-fold anisotropy governs morphological evolution and stress generation in sodiated black phosphorus for sodium ion batteries. Nano Lett 17(4):2299-2306

23. Doh CH, Ha YC, Eom SW (2019) Entropy measurement of a large format lithium ion battery and its application to calculate heat generation. Electrochim Acta 309:382-391

24. Erickson EM, Ghanty C, Aurbach D (2014) New horizons for conventional lithium ion battery technology. J Phys Chem Lett 5(19):3313-3324

25. Carbone L, Coneglian T, Gobet M et al (2018) A simple approach for making a viable, safe, and high-performances lithium-sulfur battery. J Power Sources 377:26-35

26. Schuster J, He G, Mandlmeier B et al (2012) Spherical ordered mesoporous carbon nanoparticles with high porosity for lithiumsulfur batteries. Angew Chem Int Ed 51(15):3591-3595

27. Chen W, Lei T, Qian T et al (2018) A new hydrophilic binder enabling strongly anchoring polysulfides for high-performance sulfur electrodes in lithium-sulfur battery. Adv Energy Mater $8(12): 1702889$

28. Li CC, Shi JJ, Zhu L et al (2018) Titanium nitride hollow nanospheres with strong lithium polysulfide chemisorption as sulfur hosts for advanced lithium-sulfur batteries. Nano Res 11(8):4302-4312

29. Xu J, Zhang WX, Fan HB et al (2018) Promoting lithium polysulfide/sulfide redox kinetics by the catalyzing of zinc sulfide for high performance lithium-sulfur battery. Nano Energy 51:73-82

30. Wang L, Pan J, Zhang Y et al (2018) A Li-air battery with ultralong cycle life in ambient air. Adv Mater 30(3):1704378

31. Cheng FY, Chen J (2012) Something from nothing. Nat Chem 4(12):962-963

32. Pan J, Tian XL, Zaman S et al (2019) Recent progress on transition metal oxides as bifunctional catalysts for lithium-air and zinc-air batteries. Batter Supercaps 2(4):336-347

33. Shen XW, Li YT, Qian T et al (2019) Lithium anode stable in air for low-cost fabrication of a dendrite-free lithium battery. Nat Commun 10:900

34. Fu YQ, Wei QL, Zhang GX et al (2018) Batteries: advanced phosphorus-based materials for lithium/sodium-ion batteries: recent developments and future perspectives. Adv Energy Mater $8(13): 1870057$ 
35. Liu HW, Hu K, Yan DF et al (2018) Recent advances on black phosphorus for energy storage, catalysis, and sensor applications. Adv Mater 30(32): 1800295

36. Bi S, Lu CB, Zhang WB et al (2018) Two-dimensional polymerbased nanosheets for electrochemical energy storage and conversion. J Energy Chem 27(1):99-116

37. Zhang XQ, Cheng XB, Zhang Q (2016) Nanostructured energy materials for electrochemical energy conversion and storage: a review. J Energy Chem 25(6):967-984

38. Mal P, Breiner B, Rissanen K et al (2009) White phosphorus is air-stable within a self-assembled tetrahedral capsule. Science 324(5935):1697-1699

39. Simon A, Borrmann H, Horakh J (1997) On the polymorphism of white phosphorus. Chem Ber/Recl 130(9):1235-1240

40. Zhuo ZW, Wu XJ, Yang JL (2016) Two-dimensional phosphorus porous polymorphs with tunable band gaps. J Am Chem Soc 138(22):7091-7098

41. Aykol M, Doak JW, Wolverton C (2017) Phosphorus allotropes: stability of black versus red phosphorus re-examined by means of the van der Waals inclusive density functional method. Phys Rev B 95(21):214115

42. Nitschke JR (2011) The two faces of phosphorus. Nat Chem 3(1):90

43. Caldicott DGE, Pigou PE, Beattie R et al (2005) Clandestine drug laboratories in Australia and the potential for harm. Aust N Z J Public Health 29(2):155-162

44. Vimalnath KV, Shetty P, Chakraborty S et al (2013) Practicality of production of $32 \mathrm{P}$ by direct neutron activation for its utilization in bone pain palliation as $\mathrm{Na}_{3}[32 \mathrm{P}] \mathrm{PO} 4$. Cancer Biother Radiopharm 28(5):423-428

45. Pfitzner A (2006) Phosphorus remains exciting! Angew Chem Int Ed 45(5):699-700

46. Appalakondaiah S, Vaitheeswaran G, Lebègue $\mathrm{S}$ et al (2012) Effect of van der Waals interactions on the structural and elastic properties of black phosphorus. Phys Rev B 86(3):035105

47. Akahama Y, Kawamura H, Carlson S et al (2000) Structural stability and equation of state of simple-hexagonal phosphorus to $280 \mathrm{GPa}$ : phase transition at $262 \mathrm{GPa}$. Phys Rev B 61(5):3139

48. Clark SM, Zaug JM (2010) Compressibility of cubic white, orthorhombic black, rhombohedral black, and simple cubic black phosphorus. Phys Rev B 82(13):134111

49. Zhang JL, Zhao ST, Han C et al (2016) Epitaxial growth of single layer blue phosphorus: a new phase of two-dimensional phosphorus. Nano Lett 16(8):4903-4908

50. Bridgman PW (1914) Two new modifications of phosphorus. J Am Chem Soc 36(7):1344-1363

51. Shirotani I, Maniwa R, Sato H et al (1981) Preparation, growth of large single-crystals, and physicochemical properties of black phosphorus at high-pressures and temperatures. Nippon Kagaku Kaishi 10:1604-1609

52. Akahama Y, Endo S, Narita SI (1983) Electrical properties of black phosphorus single crystals. J Phys Soc Jpn 52(6):2148-2155

53. Park CM, Sohn HJ (2007) Black phosphorus and its composite for lithium rechargeable batteries. Adv Mater 19(18):2465-2468

54. Nilges T, Kersting M, Pfeifer T (2008) A fast low-pressure transport route to large black phosphorus single crystals. J Solid State Chem 181(8):1707-1711

55. Wu RJ, Topsakal M, Low T et al (2015) Atomic and electronic structure of exfoliated black phosphorus. J Vac Sci Technol A Vac Surfaces Films 33(6):060604

56. Han C, Hu ZH, Carvalho A et al (2017) Oxygen induced strong mobility modulation in few-layer black phosphorus. Mater 4(2):021007
57. Luo Z, Maassen J, Deng YX et al (2015) Anisotropic in-plane thermal conductivity observed in few-layer black phosphorus. Nat Commun 6:8572

58. Li WF, Yang YM, Zhang G et al (2015) Ultrafast and directional diffusion of lithium in phosphorene for high-performance lithium-ion battery. Nano Lett 15(3):1691-1697

59. Choi H, Lee S, Eom K (2019) Facile phosphorus-embedding into $\mathrm{SnS}_{2}$ using a high-energy ball mill to improve the surface kinetics of P-SnS ${ }_{2}$ anodes for a Li-ion battery. Appl Surf Sci 466:578-582

60. Xiao W, Sun Q, Banis MN et al (2019) Unveiling the interfacial instability of the phosphorus/carbon anode for sodium-ion batteries. ACS Appl Mater Interfaces 11(34):30763-30773

61. Chen ZY, Zhu YB, Wang QM et al (2019) Fibrous phosphorus: a promising candidate as anode for lithium-ion batteries. Electrochim Acta 295:230-236

62. Hembram KPSS, Jung H, Yeo BC et al (2016) A comparative first-principles study of the lithiation, sodiation, and magnesiation of black phosphorus for Li-, Na-, and Mg-ion batteries. Phys Chem Chem Phys 18(31):21391-21397

63. Kuo PH, Du JC (2019) Lithium ion diffusion mechanism and associated defect behaviors in crystalline $\mathrm{Li}^{1+} \mathrm{xAlxGe}_{2-\mathrm{x}}\left(\mathrm{PO}_{4}\right)_{3}$ solid-state electrolytes. J Phys Chem C 123(45):27385-27398

64. Cui YH, Zhao Y, Chen $\mathrm{H}$ et al (2018) First-principles study of $\mathrm{MoO}_{3}$ /graphene composite as cathode material for high-performance lithium-ion batteries. Appl Surf Sci 433:1083-1093

65. Sun J, Lee HW, Pasta M et al (2015) A phosphorene-graphene hybrid material as a high-capacity anode for sodium-ion batteries. Nat Nanotech 10(11):980-985

66. Luo YF, Wu HC, Liu L et al (2018) $\mathrm{TiO}_{2}$-nanocoated black phosphorus electrodes with improved electrochemical performance. ACS Appl Mater Interfaces 10(42):36058-36066

67. Sun J, Zheng GY, Lee HW et al (2014) Formation of stable Phosphorus-Carbon bond for enhanced performance in black phosphorus Nanoparticle-Graphite composite battery anodes. Nano Lett 14(8):4573-4580

68. Li XY, Chen G, Le ZY et al (2019) Well-dispersed phosphorus nanocrystals within carbon via high-energy mechanical milling for high performance lithium storage. Nano Energy $59: 464-471$

69. Jiao XX, Liu YY, Li B et al (2019) Amorphous phosphoruscarbon nanotube hybrid anode with ultralong cycle life and highrate capability for lithium-ion batteries. Carbon 148:518-524

70. Xu GL, Chen ZH, Zhong GM et al (2016) Nanostructured black phosphorus/Ketjenblack-Multiwalled carbon nanotubes composite as high performance anode material for sodium-ion batteries. Nano Lett 16(6):3955-3965

71. Zhao D, Zhang LH, Fu CC et al (2018) Hierarchical phosphorus hybrids with carbon nanotube veins and black phosphorus skins: structure and lithium storage properties. Carbon 139:1057-1062

72. Haghighat-Shishavan S, Nazarian-Samani M, Nazarian-Samani M et al (2018) Strong, persistent superficial oxidation-assisted chemical bonding of black phosphorus with multiwall carbon nanotubes for high-capacity ultradurable storage of lithium and sodium. J Mater Chem A 6(21):10121-10134

73. Ryder CR, Wood JD, Wells SA et al (2016) Covalent functionalization and passivation of exfoliated black phosphorus via aryl diazonium chemistry. Nat Chem 8(6):597-602

74. Hanlon D, Backes C, Doherty E et al (2015) Liquid exfoliation of solvent-stabilized few-layer black phosphorus for applications beyond electronics. Nat Commun 6:8563

75. Guo ZN, Zhang H, Lu SB et al (2015) From black phosphorus to phosphorene: basic solvent exfoliation, evolution of Raman scattering, and applications to ultrafast photonics. Adv Funct Mater 25(45):6996-7002 
76. Ambrosi A, Sofer Z, Pumera M (2017) Electrochemical exfoliation of layered black phosphorus into phosphorene. Angew Chem Int Ed 56(35):10443-10445

77. Smith JB, Hagaman D, Ji HF (2016) Growth of 2D black phosphorus film from chemical vapor deposition. Nanotechnology 27(21):215602

78. Zhang YY, Rui XH, Tang YX et al (2016) Wet-chemical processing of phosphorus composite nanosheets for high-rate and highcapacity lithium-ion batteries. Adv Energy Mater 6(10):1502409

79. Chen L, Zhou GM, Liu ZB et al (2016) Scalable clean exfoliation of high-quality few-layer black phosphorus for a flexible lithium ion battery. Adv Mater 28(3):510-517

80. Shuai HL, Ge P, Hong WW et al (2019) Electrochemically exfoliated phosphorene-graphene hybrid for sodium-ion batteries. Small Methods 3(2):1800328

81. Liu YH, Liu QZ, Zhang AY et al (2018) Room-temperature pressure synthesis of layered black Phosphorus-Graphene composite for sodium-ion battery anodes. ACS Nano 12(8):8323-8329

82. Jin HC, Zhang TM, Chuang CH et al (2019) Synergy of black Phosphorus-Graphite-Polyaniline-based ternary composites for stable high reversible capacity Na-ion battery anodes. ACS Appl Mater Interfaces 11(18):16656-16661

83. Mei J, Zhang YW, Liao T et al (2019) Black phosphorus nanosheets promoted $2 \mathrm{D}-\mathrm{TiO}_{2}-2 \mathrm{D}$ heterostructured anode for high-performance lithium storage. Energy Storage Mater 19:424-431

84. Meng RJ, Huang JM, Feng YT et al (2018) Black phosphorus quantum dot/Ti3C2MXene nanosheet composites for efficient electrochemical lithium/sodium-ion storage. Adv Energy Mater 8(26): 1801514

85. Xu RC, Zhang SZ, Wang XL et al (2018) Recent developments of all-solid-state lithium secondary batteries with sulfide inorganic electrolytes. Chem Eur J 24(23):6007-6018

86. Zhou F, Li Z, Lu YY et al (2019) Diatomite derived hierarchical hybrid anode for high performance all-solid-state lithium metal batteries. Nat Commun 10:2482

87. Kim A, Jung H, Song J et al (2019) Lithium-ion intercalation into graphite in $\mathrm{SO}_{2}{ }^{-}$Based inorganic electrolyte toward highrate-capable and safe lithium-ion batteries. ACS Appl Mater Interfaces 11(9):9054-9061

88. Nagao M, Hayashi A, Tatsumisago M (2011) All-solidstate lithium secondary batteries with high capacity using black phosphorus negative electrode. J Power Sources 196(16):6902-6905

89. Agnihotri S, Rastogi P, Chauhan YS et al (2018) Significant enhancement of the Stark effect in rippled monolayer blue phosphorus. J Phys Chem C 122(9):5171-5177

90. Li QF, Duan CG, Wan XG et al (2015) Theoretical prediction of anode materials in Li-ion batteries on layered black and blue phosphorus. J Phys Chem C 119(16):8662-8670

91. Mukherjee S, Kavalsky L, Singh CV (2018) Ultrahigh storage and fast diffusion of $\mathrm{Na}$ and $\mathrm{K}$ in blue phosphorene anodes. ACS Appl Mater Interfaces 10(10):8630-8639

92. Fan KM, Tang T, Wu SY et al (2018) Graphene/blue-phosphorus heterostructure as potential anode materials for sodium-ion batteries. Int J Mod Phys B 32(1):1850010

93. Pramudita JC, Sehrawat D, Goonetilleke D et al (2017) An initial review of the status of electrode materials for potassiumion batteries. Adv Energy Mater 7(24):1602911

94. Wu XY, Leonard DP, Ji XL (2017) Emerging non-aqueous potassium-ion batteries: challenges and opportunities. Chem Mater 29(12):5031-5042

95. Vaalma C, Giffin GA, Buchholz D et al (2016) Non-aqueous $\mathrm{K}$-ion battery based on layered $\mathrm{K}_{03} \mathrm{MnO}_{2}$ and hard carbon/carbon black. J Electrochem Soc 163(7):1295-1299
96. Zhang WC, Liu YJ, Guo ZP (2019) Approaching high-performance potassium-ion batteries via advanced design strategies and engineering. Sci Adv 5(5):7412. https://doi.org/10.1126/ sciadv.aav7412

97. Vaalma C, Buchholz D, Passerini S (2018) Non-aqueous potassium-ion batteries: a review. Curr Opin Electrochem 9:41-48

98. Zhang WC, Mao JF, Li SA et al (2017) Phosphorus-based alloy materials for advanced potassium-ion battery anode. $\mathrm{J}$ Am Chem Soc 139(9):3316-3319

99. Sultana I, Rahman MM, Ramireddy T et al (2017) High capacity potassium-ion battery anodes based on black phosphorus. J Mater Chem A 5(45):23506-23512

100. Wu X, Zhao W, Wang H et al (2018) Enhanced capacity of chemically bonded phosphorus/carbon composite as an anode material for potassium-ion batteries. J Power Sources 378:460-467

101. Singh N, Arthur TS, Ling C et al (2013) A high energy-density tin anode for rechargeable magnesium-ion batteries. Chem Commun 49(2):149-151

102. Kim RH, Kim JS, Kim HJ et al (2014) Highly reduced VOx nanotube cathode materials with ultra-high capacity for magnesium ion batteries. J Mater Chem A 2(48):20636-20641

103. Han XP, Liu C, Sun J et al (2018) Density functional theory calculations for evaluation of phosphorene as a potential anode material for magnesium batteries. RSC Adv 8(13):7196-7204

104. Jin W, Wang ZG, Fu YQ (2016) Monolayer black phosphorus as potential anode materials for Mg-ion batteries. J Mater Sci 51(15):7355-7360

105. Hou TZ, Chen X, Peng HJ et al (2016) Design principles for heteroatom-doped nanocarbon to achieve strong anchoring of polysulfides for lithium-sulfur batteries. Small 12(24):3283-3291

106. Liu M, Deng N, Ju J et al (2019) A review: electrospun nanofiber materials for lithium-sulfur batteries. Adv Funct Mater 29:1905467

107. He JR, Manthiram A (2019) A review on the status and challenges of electrocatalysts in lithium-sulfur batteries. Energy Storage Mater 20:55-70

108. Zhang ZA, Wang GC, Lai YQ et al (2015) Nitrogen-doped porous hollow carbon sphere-decorated separators for advanced lithium-sulfur batteries. J Power Sources 300:157-163

109. Zhang LL, Wan F, Wang XY et al (2018) Dual-functional graphene carbon as polysulfide trapper for high-performance lithium sulfur batteries. ACS Appl Mater Interfaces 10(6):5594-5602

110. Xiang KX, Chen MF, Hu J et al (2019) Intertwined nitrogendoped carbon nanotube microsphere as polysulfide grappler for high-performance lithium-sulfur batteries. ChemElectroChem 6(5): $1466-1474$

111. Wu JY, Li XW, Zeng HX et al (2019) Fast electrochemical kinetics and strong polysulfide adsorption by a highly oriented $\mathrm{MoS}_{2}$ nanosheet@N-doped carbon interlayer for lithium-sulfur batteries. J Mater Chem A 7(13):7897-7906

112. Gao XT, Zhu XD, Gu LL et al (2019) Efficient polysulfides anchoring for Li-S batteries: combined physical adsorption and chemical conversion in $\mathrm{V}_{2} \mathrm{O}_{5}$ hollow spheres wrapped in nitrogen-doped graphene network. Chem Eng J 378:122189

113. Majumder S, Shao MH, Deng YF et al (2019) Two dimensional $\mathrm{WS}_{2} / \mathrm{C}$ nanosheets as a polysulfides immobilizer for high performance lithium-sulfur batteries. J Electrochem Soc 166(3):A5386-A5395

114. Sun J, Sun YM, Pasta M et al (2016) Entrapment of polysulfides by a black-phosphorus-modified separator for lithium-sulfur batteries. Adv Mater 28(44):9797-9803

115. Li L, Chen L, Mukherjee S et al (2017) Phosphorene as a polysulfide immobilizer and catalyst in high-performance lithiumsulfur batteries. Adv Mater 29(2):1602734 
116. Xu ZL, Lin SH, Onofrio N et al (2018) Exceptional catalytic effects of black phosphorus quantum dots in shuttling-free lithium sulfur batteries. Nat Commun 9:4164

117. Mukherjee S, Kavalsky L, Chattopadhyay K et al (2018) Adsorption and diffusion of lithium polysulfides over blue phosphorene for Li-S batteries. Nanoscale 10(45):21335-21352

118. Zhang Y, Wang L, Guo ZY et al (2016) High-performance lithium-air battery with a coaxial-fiber architecture. Angew Chem Int Ed 55(14):4487-4491

119. Liu T, Feng XL, Jin X et al (2019) Protecting the lithium metal anode for a safe flexible lithium-air battery in ambient air. Angew Chem 131(50):18408-18413

120. Girishkumar G, McCloskey B, Luntz AC et al (2010) Lithium-Air battery: promise and challenges. J Phys Chem Lett 1(14):2193-2203

121. Yuan J, Yu JS, Sundén B (2015) Review on mechanisms and continuum models of multi-phase transport phenomena in porous structures of non-aqueous Li-Air batteries. J Power Sources 278:352-369

122. Kim Y, Koo D, Ha S et al (2018) Two-dimensional phosphorenederived protective layers on a lithium metal anode for lithiumoxygen batteries. ACS Nano 12(5):4419-4430

123. Lu YC, Gasteiger HA, Shao-Horn Y (2011) Catalytic activity trends of oxygen reduction reaction for nonaqueous Li-air batteries. J Am Chem Soc 133(47):19048-19051

124. Esfahanian V, Dalakeh MT, Aghamirzaie N (2019) Mathematical modeling of oxygen crossover in a lithium-oxygen battery. Appl Energy 250:1356-1365

125. Salehi M, Shariatinia Z, Sadeghi A (2019) Application of RGO/ CNT nanocomposite as cathode material in lithium-air battery. J Electroanal Chem 832:165-173

126. Jung HG, Hassoun J, Park JB et al (2012) An improved highperformance lithium-air battery. Nature Chem 4(7):579-585

127. Cheng H, Xie J, Cao GS et al (2019) Realizing discrete growth of thin $\mathrm{Li}_{2} \mathrm{O}_{2}$ sheets on black phosphorus quantum dots-decorated $\delta-\mathrm{MnO}_{2}$ catalyst for long-life lithium-oxygen cells. Energy Storage Mater 23:684-692

128. Yao WT, Yuan YF, Tan GQ et al (2019) Tuning $\mathrm{Li}_{2} \mathrm{O}_{2}$ formation routes by facet engineering of $\mathrm{MnO}_{2}$ cathode catalysts. J Am Chem Soc 141(32):12832-12838

129. Lee H, Lee DJ, Kim YJ et al (2015) A simple composite protective layer coating that enhances the cycling stability of lithium metal batteries. J Power Sources 284:103-108

130. Freunberger SA, Chen YH, Peng ZQ et al (2011) Reactions in the rechargeable Lithium-O2Battery with alkyl carbonate electrolytes. J Am Chem Soc 133(20):8040-8047

131. Tan $\mathrm{P}$, Wei $\mathrm{ZH}$, Shyy W et al (2016) A nano-structured $\mathrm{RuO}_{2} /$ $\mathrm{NiO}$ cathode enables the operation of non-aqueous lithium-air batteries in ambient air. Energy Environ Sci 9(5):1783-1793

132. Xiao Y, Wang JR, Wang Y et al (2019) A new promising catalytic activity on blue phosphorene nitrogen-doped nanosheets for the ORR as cathode in nonaqueous Li-air batteries. Appl Surf Sci 488:620-628

133. Cao JY, He P, Brent JR et al (2018) Supercapacitor electrodes from the in situ reaction between two-dimensional sheets of black phosphorus and graphene oxide. ACS Appl Mater Interfaces 10(12):10330-10338
134. Zu L, Gao X, Lian HQ et al (2019) Electrochemical prepared phosphorene as a cathode for supercapacitors. J Alloy Compd 770:26-34

135. Hao CX, Yang BC, Wen FS et al (2016) Flexible all-solid-state supercapacitors based on liquid-exfoliated black-phosphorus nanoflakes. Adv Mater 28(16):3194-3201

136. Wen M, Liu DN, Kang YH et al (2019) Synthesis of high-quality black phosphorus sponges for all-solid-state supercapacitors. Mater Horiz 6(1):176-181

137. Yang BC, Hao CX, Wen FS et al (2017) Flexible black-phosphorus nanoflake/carbon nanotube composite paper for highperformance all-solid-state supercapacitors. ACS Appl Mater Interfaces 9(51):44478-44484

138. Luo SJ, Zhao JL, Zou JF et al (2018) Self-standing polypyrrole/ black phosphorus laminated film: promising electrode for flexible supercapacitor with enhanced capacitance and cycling stability. ACS Appl Mater Interfaces 10(4):3538-3548

139. Wu XJ, Xu YJ, Hu Y et al (2018) Microfluidic-spinning construction of black-phosphorus-hybrid microfibres for non-woven fabrics toward a high energy density flexible supercapacitor. Nat Commun 9:4573

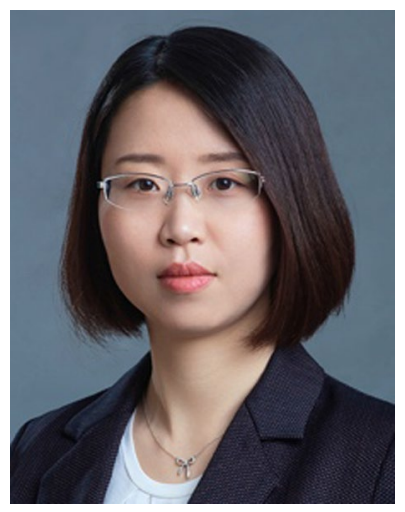

Jie Sun is a professor at the Tianjin University, China. She earned her Ph.D. from the Beijing University of Chemical Technology and then worked as a postdoctoral at the Stanford University. Her current research interests focus on the development of multifunctional nanomaterials for energy conversion and storage, including Li-ion, Na-ion, $\mathrm{K}$-ion, and $\mathrm{Mg}$-ion batteries, lithium-sulfur batteries, as well as electrocatalysis.

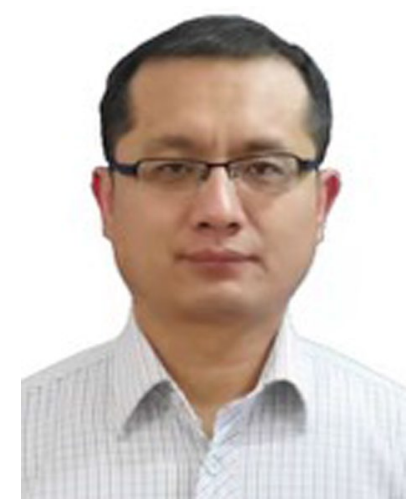

Aibing Chen is a professor at Hebei University of Science and Technology, China. He earned his Ph.D. from Dalian Institute of Chemical Physics, Chinese Academy of Sciences. His research interests are focused on the fields of physical chemistry of materials, porous materials and its applications in energy conversion and storage, adsorption separation, $\mathrm{CO}_{2}$ capture and conversion, catalytic conversion. 